\title{
Concomitant Effects of Transition Metal Chelation and Solvent Polarity on the First Molecular Hyperpolarizability of 4-Methoxyacetophenone Thiosemicarbazone: A DFT Study
}

\author{
Nyiang Kennet Nkungli and Julius Numbonui Ghogomu \\ Laboratory of Noxious Chemistry and Environmental Engineering, Department of Chemistry, Faculty of Science, \\ University of Dschang, P.O. Box 67, Dschang, Cameroon \\ Correspondence should be addressed to Julius Numbonui Ghogomu; ghogsjuju@hotmail.com
}

Received 2 July 2016; Accepted 4 October 2016

Academic Editor: Anton Kokalj

Copyright (c) 2016 N. K. Nkungli and J. N. Ghogomu. This is an open access article distributed under the Creative Commons Attribution License, which permits unrestricted use, distribution, and reproduction in any medium, provided the original work is properly cited.

\begin{abstract}
Nonlinear optical (NLO) properties of organic and metal-organic materials are of considerable interest to emerging optoelectronic and photonic technologies. Much work has been carried out on the former materials but the latter ones have received less attention till date. Herein, a density functional theory (DFT) study on the combined effects of transition metal chelation and solvent polarity on the first hyperpolarizability $\left(\beta_{\text {tot }}\right)$ of 4 -methoxyacetophenone thiosemicarbazone (MAPTSC) is reported. MAPTSC exhibits a tautomeric form with higher optical nonlinearity rendering its NLO response in polar solvents potentially switchable. Our results have revealed significant modifications of the first hyperpolarizability of MAPTSC upon complexation with different transition metal chlorides in the presence of solvents with varying dielectric constants. Therefore, its second-order NLO response is highly tunable by the synergy of transition metal chelation and solvent polarity. MAPTSC and its $\mathrm{Zn}$ (II) and Pt(II) chloride complexes are promising NLO materials because their gas-phase $\beta_{\text {tot }}$ values are larger than those of the prototype push-pull molecules, paranitroaniline (PNA) and urea, by factors of about 1.40-1.76 and 19.57-37.24, respectively; these factors greatly increase in polar solvent medium. Moreover, they possess high optical transparencies in the visible region of the electromagnetic spectrum which mitigate transparency/nonlinearity trade-offs, thereby increasing the likelihood of broad band NLO response.
\end{abstract}

\section{Introduction}

Nonlinear optical (NLO) materials have recently received considerable attention because of their potential applications in the optoelectronic and all-optical (photonic) devices of telecommunication, optical switching, optical signal processing, optical transmission, optical data storage, optical computing, and so forth, $[1,2]$. They are also essential for photodynamic therapy, biological imaging, and the protection of human eyes and optical sensors (by NLO materials with optical limiting effects) from high intensity LASER beams $[3,4]$. NLO effects arise from the interaction of an applied optical field (usually LASER) with the electronic field created by the oscillation of electrons in a NLO material, generating a new optical field that is altered in frequency, amplitude, phase, or any other physical property [5-7].
Very high light intensities typically provided by LASERS are required for optical nonlinearity to be observed [8]. NLO effects include saturable absorption (SA), reverse saturable absorption (RSA), second-harmonic generation (SHG), twophoton absorption (TPA), and optical limiting $[8,9]$.

Recently, the first hyperpolarizability $\left(\beta_{\text {tot }}\right)$ has been under rigorous investigation because a large $\beta_{\text {tot }}$ value is a prerequisite for large and fast second-order or quadratic NLO response. Other necessary conditions for significant quadratic NLO properties in molecular materials include noncentrosymmetry, low optical loss, high thermal and mechanical stability, intense low-energy electronic transitions with charge transfer (CT) character, and significant intramolecular charge transfer (ICT) owing to electron cloud movement from an electron donor to an electron acceptor through a $\pi$-conjugate bridge $[10,11]$. Molecules with 
excellent NLO properties usually contain an electron-donor group (D) and an electron-acceptor group (A) linked through an intervening $\pi$-conjugated framework, forming the socalled D- $\pi$-A structure or push-pull system $[12,13]$. Effective methods of enhancing the second-order NLO responses of materials involve increasing the donor-acceptor capabilities of $\mathrm{D}$ and $\mathrm{A}$ and increasing the length of the $\pi$-conjugated pathway between them $[2,9,14]$.

Important candidates in the area of NLO chromophores are organic and metal-organic materials. For the latter, transition metal complexes with $\pi$-conjugated ligands are interesting for the construction of multifunctional NLO chromophores by virtue of their rich photochemical and photophysical properties, greater design flexibility, excellent chemical stability, and intense low-energy metal-to-ligand charge transfer (MLCT), as well as ligand-to-metal charge transfer (LMCT) electronic transitions $[2,15]$. From literature survey, the vast majority of molecules investigated for NLO effects are purely organic push-pull systems. Comparatively, transition metal complexes containing $\pi$-conjugated organics are less explored in this area despite their potentials of combining the high optical nonlinearity and chemical flexibility of organic materials with the physical ruggedness of inorganic materials. In an effort to bridge this gap, the impact of metal complexation on the NLO responses of purely organic push-pull systems is currently being investigated. In this perspective, we chose 4-methoxyacetophenone thiosemicarbazone (MAPTSC) as our organic push-pull system because thiosemicarbazones and their metal complexes are notable materials for SHG and, as such, are highly applicable in the field of nonlinear optics [16]. The extensive electron delocalization in the thiosemicarbazone (TSC) moiety greatly improves the SHG efficiency of free TSC ligands and their metal complexes [17]. Furthermore, acetophenone thiosemicarbazone (APTSC) has been identified by means of the Zscan technique as a NLO material with third-order harmonic generation capability [17]. Because MAPTSC has a powerful electron donor $\left(-\mathrm{OCH}_{3}\right)$ appended to the benzene ring which is not the case in APTSC. The NLO response of the former is expected to be larger and faster than that of the latter. Moreover, MAPTSC like many TSCs readily forms chelates with transition metals. Several of its transition metal complexes, including most of those currently studied, have been successfully synthesized, crystallized, and characterized [18].

Herein, we report for the first time on the combined effects of transition metal coordination by MAPTSC and solvent polarity and on its first molecular hyperpolarizability. Specifically, the $\beta_{\text {tot }}$ values of MAPTSC and its $\mathrm{Ni}(\mathrm{II}), \mathrm{Pd}(\mathrm{II})$, $\mathrm{Pt}(\mathrm{II}), \mathrm{Cu}(\mathrm{II})$, and $\mathrm{Zn}$ (II) chloride complexes in vacuo and in solvents with different dielectric constants have been calculated and compared. In an attempt to explain the modifications undergone by the $\beta_{\text {tot }}$ value of MAPTSC following its complexation with different transition metal ions and due to changes in solvent polarity, the relationship between $\beta_{\text {tot }}$ values of all molecules studied and their frontier molecular orbital (HOMO-LUMO) energy gaps has been sought. In the same vein, the relationship between these $\beta_{\text {tot }}$ values and photoinduced electronic transitions in the molecules has been investigated. Time-dependent density functional theory (TD-DFT) calculations, natural bond orbital (NBO) analysis, and charge decomposition analysis (CDA) have been carried out in order to determine the charge transfer (CT) capabilities, optical transparencies in the visible region of the electromagnetic (EM) spectrum, electron delocalization, and orbital interaction patterns of the molecules. Owing to the complications encountered during the experimental measurement of NLO activities of materials by the Zscan technique, quantum chemical calculations remain a fascinating alternative. For this study, the density functional theory (DFT) was preferred over $a b$ initio methods because DFT calculations, with pseudopotentials, are the standard approach for computations on transition metal containing systems [19]. Moreover, the DFT is very instrumental in designing molecules for NLO applications [14] because of its remarkable accuracy/computational-time ratio, coupled with the fact that it takes good account of electron correlation effects in calculations.

\section{Computational Details and Background Theory on Second-Order NLO Response}

All theoretical calculations were carried out with the Gaussian 09W suite of programs [20]. The molecular geometries of MAPTSC and its $\mathrm{Ni}(\mathrm{II}), \mathrm{Pd}(\mathrm{II}), \mathrm{Pt}(\mathrm{II}), \mathrm{Cu}(\mathrm{II})$, and $\mathrm{Zn}(\mathrm{II})$ chloride complexes were optimized without constraints of any kind in gas and solvent phases using Becke's threeparameter Lee-Yang-Parr hybrid functional [21] in conjunction with the small core Stuttgart-Dresden pseudopotential (SDD) for the transition metals, and the Pople-style basis set $6-31++G(d, p)$ for every other element. Then, harmonic vibrational frequencies were computed at the same level of theory as that used for geometry optimization to ascertain that each of the optimized geometries is a local minimum on its potential energy surface. For all calculations reported herein, the restricted closed-shell Kohn-Sham model was adopted for the closed-shell molecules (MAPTSC and its $\mathrm{Ni}(\mathrm{II})$, $\mathrm{Pd}(\mathrm{II}), \mathrm{Pt}(\mathrm{II})$, and $\mathrm{Zn}$ (II) chloride complexes), whereas the unrestricted Kohn-Sham model was used for the open-shell $\mathrm{Cu}$ (II) chloride complex.

Bulk solvent effects were taken into account by the integral equation formalism polarizable continuum model (IEF-PCM). Three types of solvents, namely, benzene (a nonpolar solvent), ethanol (a polar protic solvent), and dimethyl sulfoxide, DMSO (a polar aprotic solvent), were used for investigation of solvent effects on the first hyperpolarizabilities of the molecules studied. For all compounds investigated, first hyperpolarizability $\left(\beta_{\text {tot }}\right)$ values were calculated at the B3LYP/6-31++G(d,p)/(SDD for metal ions) and B3LYP/6-311++G(d,p)/(SDD for metal ions) levels of theory, for comparison. Vertical excitation energies to the first 10 singlet excited states were computed using TDDFT method at CAM-B3LYP/6-31++G(d,p)/(SDD for metal ions) level of theory. The corrected asymptotic behavior of the CAM-B3LYP (Coulomb-attenuating method applied to B3LYP) functional improves accuracy especially in the higher regions of the electronic spectrum. Natural transition orbital (NTO) analyses were performed in order to describe the 
singlet "particle-hole" pairs involved in the dominant electronic transitions in all molecules studied. Natural transition orbitals (NTOs) provide a better qualitative description of electronic excitations. They are obtained by transforming the canonical molecular orbitals into a more compact form in which each excited state is most often represented by a single pair of orbitals, the "particle" and the "hole." An electronic excitation from "particle" to "hole" is weighted with an eigenvalue [22].

The first molecular hyperpolarizabilities of MAPTSC and its complexes were calculated by the finite field method as implemented in Gaussian 09W. In a static electric field $F$, the energy of an isolated molecule can be written as a Taylor series expansion with respect to the electric field, as shown in the following equation $[5,23]$ :

$$
\begin{aligned}
E= & E_{0}-\mu_{i} F_{i}-\frac{1}{2} \alpha_{i j} F_{i} F_{j}-\frac{1}{6} \beta_{i j k} F_{i} F_{j} F_{k} \\
& -\frac{1}{24} \gamma_{i j k l} F_{i} F_{j} F_{k} F_{l}-\cdots .
\end{aligned}
$$

In this equation, $E_{0}$ is the energy of the unperturbed molecule (the molecular energy without the applied electric field), $F_{i}$ is the field at the origin, $\mu_{i}$ is the permanent dipole moment vector, and $\alpha_{i j}, \beta_{i j k}$, and $\gamma_{i j k l}$ are the polarizability, first static hyperpolarizability, and second static hyperpolarizability tensors, respectively. The subscripts $i, j$, and $k$ label the $x, y$, and $z$ components, since the external electric field is applied to the molecule with coordinates along $x, y$, and $z$ directions [13, 24]. The first static hyperpolarizability tensor $\beta_{\text {tot }}$ is defined as

$$
\beta_{\mathrm{tot}}=\left(\beta_{x}^{2}+\beta_{y}^{2}+\beta_{z}^{2}\right)^{1 / 2}
$$

where $\beta_{x}, \beta_{y}$, and $\beta_{z}$ are the components of $\beta_{\text {tot }}$ along the $x$, $y$, and $z$ axes, respectively $[23,25,26]$. From the components of the $\beta_{\text {tot }}$ tensor, the values of $\beta_{x}, \beta_{y}$, and $\beta_{z}$ are calculated as follows:

$$
\begin{aligned}
& \beta_{x}=\left(\beta_{x x x}+\beta_{x y y}+\beta_{x z z}\right) ; \\
& \beta_{y}=\left(\beta_{y y y}+\beta_{y z z}+\beta_{y x x}\right) ; \\
& \beta_{z}=\left(\beta_{z z z}+\beta_{z x x}+\beta_{z y y}\right) .
\end{aligned}
$$

Therefore, the complete equation used to calculate the magnitude of $\beta_{\text {tot }}$ is

$$
\begin{aligned}
& \beta_{\mathrm{tot}}=\left[\left(\beta_{x x x}+\beta_{x y y}+\beta_{x z z}\right)^{2}+\left(\beta_{y y y}+\beta_{y z z}+\beta_{y x x}\right)^{2}\right. \\
& \left.+\left(\beta_{z z z}+\beta_{z x x}+\beta_{z y y}\right)^{2}\right]^{1 / 2} .
\end{aligned}
$$

\section{Results and Discussion}

3.1. The Push-Pull Structures and Optimized Geometries of the Molecules Studied. MAPTSC undergoes rapid and facile thione-thiol tautomerization via the exchange of a proton between the hydrazinic nitrogen and the thionic sulfur of the thiosemicarbazone (TSC) moiety [16]. It can act as an $\mathrm{N}$ - and S-donor bidentate neutral ligand (thione tautomer) and as an anionic ligand (deprotonated thiol tautomer) [27]. Much attention in this paper has been focused on the thione tautomer of MAPTSC and its complexes because the thione tautomer is the predominant form of thiosemicarbazones [28]. The push-pull CT mechanisms of the thione tautomer (L1) and thiol tautomer (L2) of MAPTSC are depicted in Figures 1(a) and 1(b), respectively. In both tautomers, the electron donor (D) is the methoxy group $\left(-\mathrm{OCH}_{3}\right)$. The electron acceptor (A) in $\mathrm{L} 1$ and $\mathrm{L} 2$ is the hydrazinic $\mathrm{N}-\mathrm{H}$ and the amino $\left(\mathrm{NH}_{2}\right)$ groups of the TSC moiety, respectively. As such, the $\pi$-conjugated pathway linking A and D in L1 is made up of the benzene ring and the appended azomethine group of the thionic TSC moiety, while that in L2 is comprised mainly of the benzene ring and the two attached conjugated azomethine groups of the thiolic TSC moiety. Hence, the $\pi$ conjugated bridge for the D- $\pi$-A structure is shorter in L1 than that in L2, and this can lead to the tautomers exhibiting different optical nonlinearities. Based on the length of the $\pi$-bridge between $\mathrm{A}$ and $\mathrm{D}$, the NLO response of $\mathrm{L} 2$ should be stronger than that of L1. A large difference in the optical nonlinearities of the tautomers will render the NLO response of MAPTSC switchable, since L1 and L2 are both stable at room temperature and can be interchanged via thione-thiol tautomerization.

The scenario in the transition metal chloride complexes of MAPTSC is different from that in the free ligands, because L2 loses its thiolic hydrogen via deprotonation as it chelates metal ions. The loss of the thiolic hydrogen and the stability of the chelate ring hinder thione-thiol tautomerization of MAPTSC. As a result, a switchable NLO response based on thione-thiol tautomerism is least expected in the complexes. In this paper, the NLO properties of the $\mathrm{Ni}(\mathrm{II}), \mathrm{Pd}(\mathrm{II})$, $\mathrm{Pt}(\mathrm{II}), \mathrm{Cu}(\mathrm{II})$, and $\mathrm{Zn}$ (II) chloride complexes of L1 have been studied. To facilitate the presentation and comprehension of our results, the gas-phase optimized geometries of these molecules visualized using Gauss View 5.0.8 [29] are shown in Figure 2.

Charge decomposition analysis (CDA) was performed in order to determine the nature of the coordination bonds between $\mathrm{L} 1$ and the transition metal ions $\mathrm{M}$ (II) present in the metal chloride fragments $\left(\mathrm{MCl}_{2}\right)$. In addition, CDA was used to investigate the impact $\mathrm{L} 1-\mathrm{MCl}_{2}$ binding may have on the D- $\pi$-A charge transfer mechanisms in the complexes. Furthermore, CDA was used to study the influence of any ambivalent donor-acceptor behavior of the transition metals on the push-pull CT capabilities of the complexes investigated. CDA was first proposed by Dapprich and Frenking [30] and has been generalized by Xiao and $\mathrm{Lu}$ [31] from its original formulation. Besides CDA, extended charge decomposition analysis (ECDA) proposed by Gorelsky and coworkers [32] was performed. These methods are capable of providing a deep insight into how electronic charge is transferred between L1 (fragment 1) and $\mathrm{MCl}_{2}$ (fragment 2) in the complexes for charge equilibrium to be attained. Typically, CDA defines two components of intermolecular CT: forward donation ( $\sigma$-bonding) and back donation or back-bonding ( $\pi$-bonding). This has made CDA a popular method for 


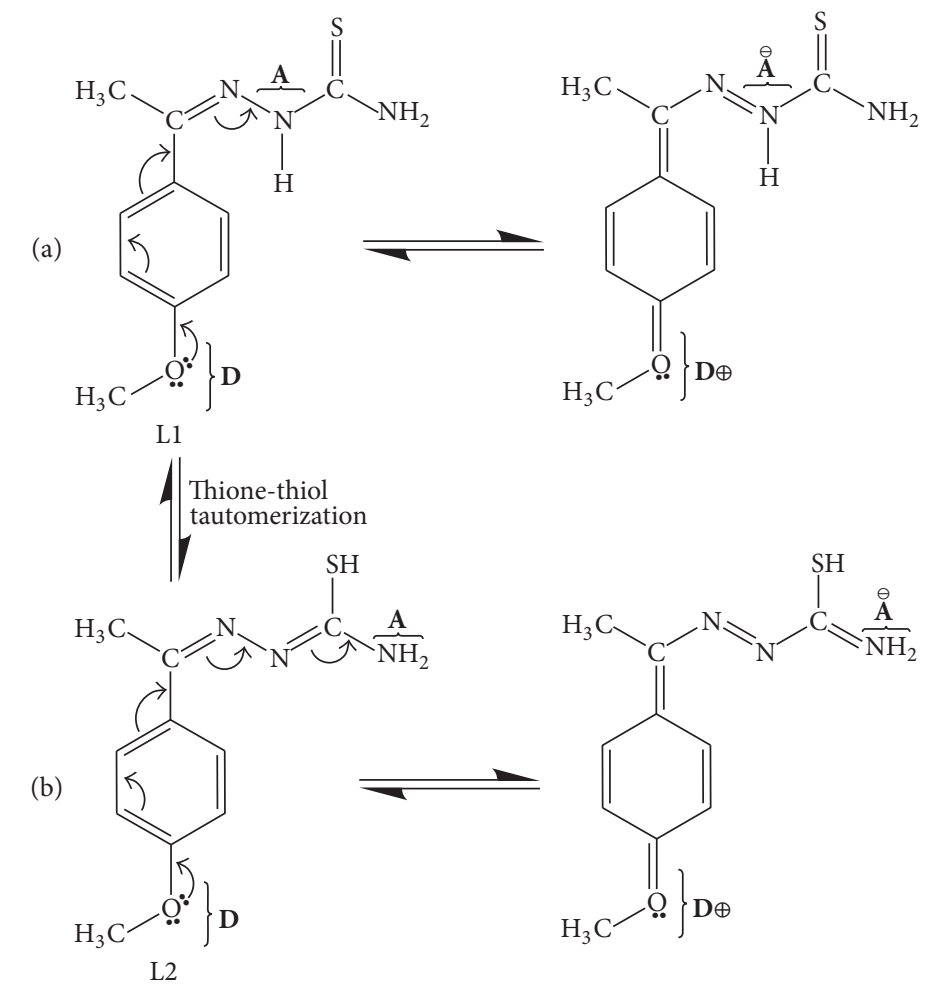

FIGURE 1: Schematic representation of the push-pull mechanisms of the thione and thiol tautomers of MAPTSC, where A is the electronacceptor group and $\mathbf{D}$ is the electron-donor group.

estimating the amount of electron delocalization in donoracceptor complexes [33] and in the donor-acceptor metalligand bonds in coordination complexes. The generalized CDA and ECDA were carried out using Multiwfn 3.3.8 [34] based on input files obtained from single-point calculations at B3LYP/6-311G(d,p)/(SDD for metal ions) level of theory. The results of CDA and ECDA on the molecules studied are presented in Table 1.

From the donation to back donation ratios, $|d / b|$ in Table 1, it is obvious that the coordination bonds in the $\mathrm{Ni}(\mathrm{II})$, $\mathrm{Cu}(\mathrm{II})$, and $\mathrm{Zn}$ (II) chloride complexes of $\mathrm{L} 1$ are predominantly sigma covalent bonds with very little $\pi$-character. The transition metal ions in these complexes act mainly as electron acceptors, since back donation is insignificant compared to donation. The electrons donated by $\mathrm{L} 1$ are mainly coming from filled $\pi$-bonding orbitals and/or the lone electron pair orbitals of its $\mathrm{N}$ - and S-donor atoms and are received in empty orbitals of the transition metal ions. The $|d / b|$ values for $\left[\mathrm{Pd}(\mathrm{L} 1) \mathrm{Cl}_{2}\right]$ and $\left[\mathrm{Pt}(\mathrm{L} 1) \mathrm{Cl}_{2}\right]$ clearly show that their coordination bonds have a substantial $\pi$ character, which helps to extend the $\pi$-conjugated pathway for the push-pull systems to the $\mathrm{Pd}(\mathrm{II})$ or $\mathrm{Pt}(\mathrm{II})$ ions in the respective complexes. The back donated electrons originate from filled $d$-orbitals of the transition metal ions and are received in empty $\pi^{*}$-antibonding orbitals on L1. The values of electron donation and back donation have shown that the $\mathrm{Pd}(\mathrm{II})$ and $\mathrm{Pt}(\mathrm{II})$ ions are capable of ambivalent electron donor-acceptor behaviors in their respective complexes studied in this research endeavor. Such ambivalent electron donor-acceptor capabilities can trigger redox processes that may lead to switchable NLO activities in the complexes. As clear from Table 1, back donation of electrons has witnessed a moderate to drastic increment in the bulk solvents, implying that the solvent environment (especially that created by the highly polar solvents) increases the $\pi$-character of the metalligand coordination bonds in the complexes investigated.

3.2. First Molecular Hyperpolarizabilities of MAPTSC and Its Complexes. The first molecular hyperpolarizabilities $\left(\beta_{\text {tot }}\right)$ of MAPTSC and its complexes studied (listed in Table 2) were calculated using (2) based on the $x, y$, and $z$ components $\left(\beta_{x}, \beta_{y}\right.$, and $\left.\beta_{z}\right)$ of $\beta_{\text {tot }}$. The values of $\beta_{x}, \beta_{y}$, and $\beta_{z}$ were computed from the components of the $\beta_{\text {tot }}$ tensor: $\beta_{x x x}$, $\beta_{y x x}, \beta_{x y y}, \beta_{y y y}, \beta_{z x x}, \beta_{x y z}, \beta_{z y y}, \beta_{x z z}, \beta_{y z z}$, and $\beta_{z z z}$, using (3). The components of the $\beta_{\text {tot }}$ tensor for each molecule studied were obtained via Gaussian 09W calculations at two levels of theory: B3LYP/6-31++G(d,p)/(SDD for metal ions) and B3LYP/6-311++G(d,p)/(SDD for metal ions) in gas and solvent phases. The trends adopted by the $\beta_{\text {tot }}$ values on going from the gas to the solvent phase have been elucidated graphically in Figure 3 . The $\beta_{\text {tot }}$ values calculated using the data obtained from Gaussian calculations are usually in atomic units, but those reported in this paper have been converted into electrostatic units using the conversion factor 1 a.u. $=8.6393 \times 10^{-33}$ esu. Inspection of the values in Table 2 and the graphs in Figure 3 has revealed similar trends adopted by the $\beta_{\text {tot }}$ values of each molecule (calculated at both levels of theory) on passing from the gas to the solvent phase. 


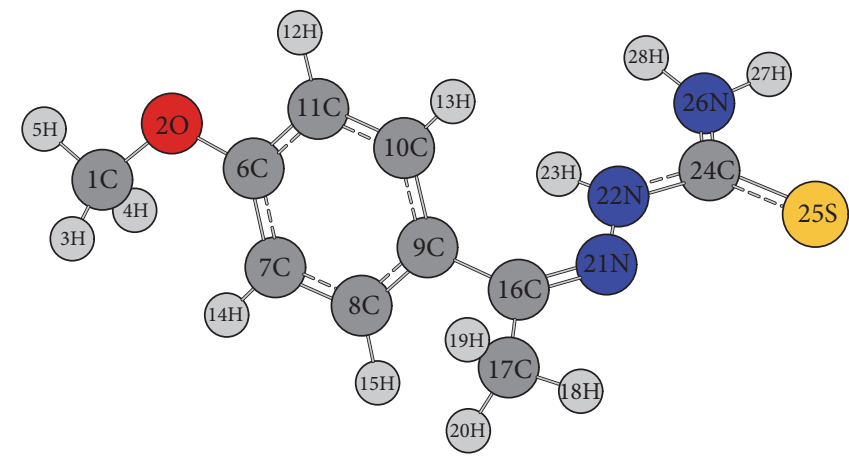

(a)

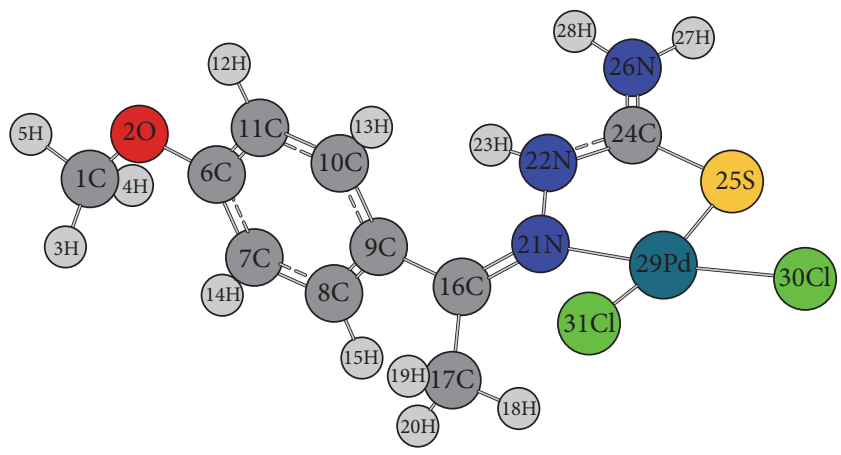

(c)

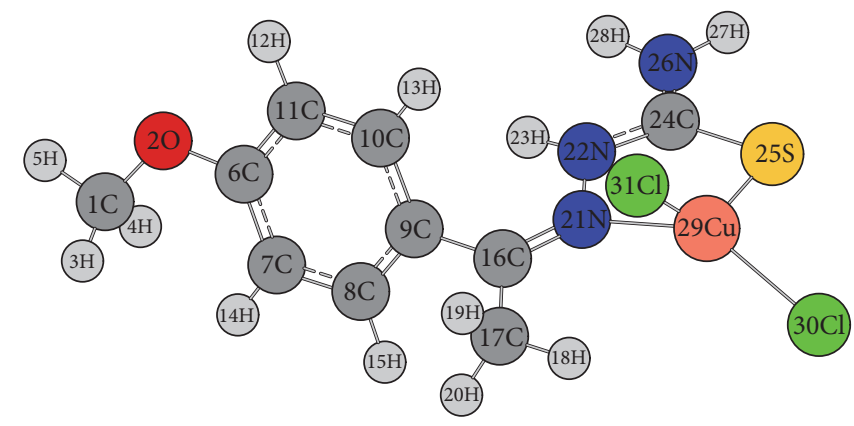

(e)

Figure 2: Optimized geometries of (a) ligand $\mathrm{L1}$, (b) $\left[\mathrm{Ni}(\mathrm{L} 1) \mathrm{Cl}_{2}\right]$, (c) $\left[\mathrm{Pd}(\mathrm{L} 1) \mathrm{Cl}_{2}\right]$, (d) $\left[\mathrm{Pt}\left(\mathrm{L}_{1}\right) \mathrm{Cl}_{2}\right],(\mathrm{e})\left[\mathrm{Cu}(\mathrm{L} 1) \mathrm{Cl}_{2}\right]$, and (f) $\left[\mathrm{Zn}(\mathrm{L} 1) \mathrm{Cl}{ }_{2}\right]$ at B3LYP/6-31++G(d,p)/(SDD for metal ions) level of theory.

Except for a few cases, the $\beta_{\text {tot }}$ values calculated at the former level of theory are larger than those calculated at the latter level. Hence, further discussion in this paper regarding the $\beta_{\text {tot }}$ values and associated second-order NLO activities of the molecules is based only on the results obtained at the B3LYP/6-31++G(d,p)/(SDD for metal ions) level of theory.

The magnitude of the $\beta_{\text {tot }}$ value for MAPTSC calculated in the present work is highly dependent on the tautomer present and on the nature of the surrounding environment. For instance, the $\beta_{\text {tot }}$ value for L1 is $7.298 \times 10^{-30}$ esu in gas-phase and $19.282 \times 10^{-30}$ esu in DMSO, while that for L2 is $11.079 \times 10^{-30}$ esu in gas-phase and $24.945 \times 10^{-30}$ esu

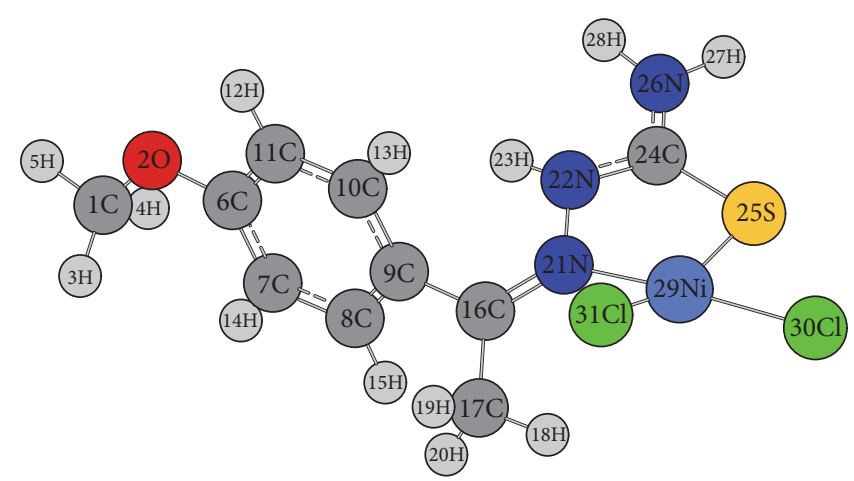

(b)

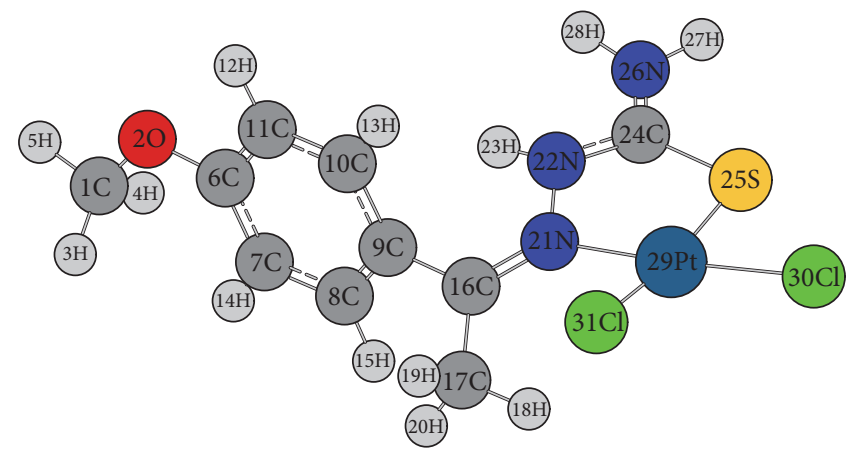

(d)

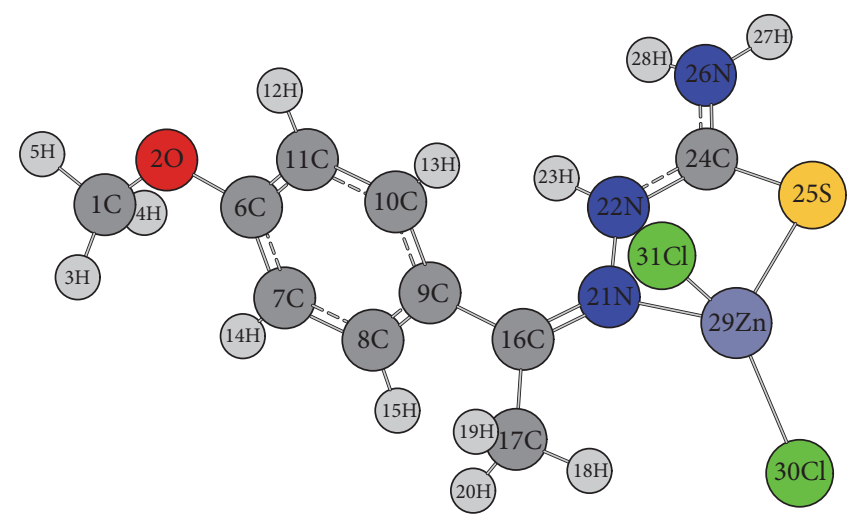

(f) in DMSO. The gas-phase $\beta_{\text {tot }}$ values of the thione-thiol tautomers of MAPTSC are approximately $0.92-1.40$ times larger than that of para-nitroaniline $\left(7.9 \times 10^{-30}\right.$ esu [35]), a prototype push-pull molecule [36], and about 19.57-29.71 times larger than that of urea $\left(372.89 \times 10^{-33}\right.$ esu [37]), indicating that MAPTSC is a potent NLO material. From the $\beta_{\text {tot }}$ values of the thione-thiol tautomers of MAPTSC, it is clear that the second-order NLO response of MAPTSC is potentially switchable especially in polar solvents, due to the presence of a tautomeric form (thiol form) with a higher CT capability. Since thione-thiol equilibrium is readily influenced by factors such as the nature of the solvent, 
TABLE 1: ECDA and generalized CDA results for transition metal chloride complexes of L1 calculated using Gaussian output files for singlepoint calculations at B3LYP/6-311G(d,p)/(SDD for metal ions) level on geometries optimized at B3LYP/6-31++G(d,p)/(SDD for metal ions) level.

\begin{tabular}{|c|c|c|c|c|c|}
\hline Complexes $^{\mathrm{a}}$ & {$\left[\mathrm{Ni}(\mathrm{L} 1) \mathrm{Cl}_{2}\right]$} & {$\left[\mathrm{Pd}(\mathrm{L} 1) \mathrm{Cl}_{2}\right]$} & {$\left[\mathrm{Pt}(\mathrm{L} 1) \mathrm{Cl}_{2}\right]$} & {$[\mathrm{Cu}(\mathrm{L} 1) \mathrm{Cl} 2]^{\mathrm{b}}$} & {$\left[\mathrm{Zn}(\mathrm{L} 1) \mathrm{Cl}_{2}\right]$} \\
\hline \multicolumn{6}{|l|}{ Gas-phase } \\
\hline Frag. $1 \rightarrow$ Frag. 2 donation $(d)$ & 0.26654 & 0.14418 & 0.21067 & 0.30532 & 0.26154 \\
\hline Frag. $1 \leftarrow$ Frag. 2 back donation $(b)$ & -0.00296 & 0.04153 & 0.05289 & -0.01265 & 0.00267 \\
\hline Net Frag.1 $\rightarrow$ Frag.2 donation $(d-b)$ & 0.26950 & 0.10266 & 0.15778 & 0.31797 & 0.25887 \\
\hline Donation to back donation ratio, $|d / b|$ & 89.95478 & 3.47205 & 3.98336 & 24.13581 & 98.02661 \\
\hline $\mathrm{CT}(1 \rightarrow 2)-\mathrm{CT}(2 \rightarrow 1)$ & 0.60450 & 0.39720 & 0.46260 & 0.56460 & 0.41070 \\
\hline \multicolumn{6}{|l|}{ Benzene } \\
\hline Frag.1 $\rightarrow$ Frag. 2 donation $(d)$ & 0.28205 & 0.15715 & 0.21982 & 0.33276 & 0.29419 \\
\hline Frag. $1 \leftarrow$ Frag. 2 back donation $(b)$ & -0.00731 & 0.03463 & 0.04368 & -0.01384 & 0.00387 \\
\hline Net Frag. $1 \rightarrow$ Frag.2 donation $(d-b)$ & 0.28936 & 0.12253 & 0.17615 & 0.34659 & 0.29032 \\
\hline Donation to back donation ratio, $|d / b|$ & 38.56248 & 4.53860 & 5.03318 & 24.05183 & 76.07706 \\
\hline $\mathrm{CT}(1 \rightarrow 2)-\mathrm{CT}(2 \rightarrow 1)$ & 0.69220 & 0.49480 & 0.55910 & 0.66880 & 0.46970 \\
\hline \multicolumn{6}{|l|}{ Ethanol } \\
\hline Frag. $1 \rightarrow$ Frag. 2 donation $(d)$ & 0.29623 & 0.16990 & 0.22919 & 0.35717 & 0.32350 \\
\hline Frag. $1 \leftarrow$ Frag. 2 back donation $(b)$ & -0.00861 & 0.02929 & 0.03645 & -0.01264 & 0.00671 \\
\hline Net Frag.1 $\rightarrow$ Frag.2 donation $(d-b)$ & 0.30484 & 0.14061 & 0.19274 & 0.36981 & 0.31679 \\
\hline Donation to back donation ratio, $|d / b|$ & 34.41757 & 5.80025 & 6.28753 & 28.25720 & 48.20414 \\
\hline $\mathrm{CT}(1 \rightarrow 2)-\mathrm{CT}(2 \rightarrow 1)$ & 0.78610 & 0.61200 & 0.67540 & 0.78440 & 0.53030 \\
\hline \multicolumn{6}{|l|}{ DMSO } \\
\hline Frag.1 $\rightarrow$ Frag. 2 donation $(d)$ & 0.29691 & 0.17013 & 0.22975 & 0.35872 & 0.32508 \\
\hline Frag. $1 \leftarrow$ Frag. 2 back donation $(b)$ & -0.00853 & 0.02883 & 0.03608 & -0.01240 & 0.00691 \\
\hline Net Frag. $1 \rightarrow$ Frag.2 donation $(d-b)$ & 0.30544 & 0.14130 & 0.19367 & 0.37112 & 0.31817 \\
\hline Donation to back donation ratio, $|d / b|$ & 34.82839 & 5.90087 & 6.36797 & 28.93394 & 47.05196 \\
\hline $\mathrm{CT}(1 \rightarrow 2)-\mathrm{CT}(2 \rightarrow 1)$ & 0.79060 & 0.61670 & 0.68310 & 0.79150 & 0.53290 \\
\hline
\end{tabular}

${ }^{a}$ Frag. refers to fragment, where Frag.1 is $\mathrm{L} 1$ and Frag. 2 is $\mathrm{MCl}_{2}[\mathrm{M}=\mathrm{Ni}(\mathrm{II}), \mathrm{Pd}(\mathrm{II}), \mathrm{Pt}(\mathrm{II}), \mathrm{Cu}(\mathrm{II})$, and $\mathrm{Zn}(\mathrm{II})]$.

${ }^{\mathrm{b}}$ The overall results for alpha and beta electrons are reported for the $\mathrm{Cu}(\mathrm{II})$ chloride complex of $\mathrm{L} 1$.

temperature, and concentration [38], the switchable NLO response of MAPTSC can be easily fine-tuned by modifying these factors.

The coordination of L1 to different transition metal centers results in significant modifications of its $\beta_{\text {tot }}$ value. Further modifications of this value are observed in the presence of bulk solvents especially the highly polar ones. Therefore, the first hyperpolarizability vis-a-vis the secondorder NLO response of L1 can be highly tuned by coordination to different transition metal ions and by the presence of solvents with different dielectric constants. The complexation of $\mathrm{L} 1$ with $\mathrm{Zn}$ (II) and $\mathrm{Pt}$ (II) chlorides results in a modest to drastic increments of its gas-phase $\beta_{\text {tot }}$ value, respectively. Unexpectedly, the complexation of $\mathrm{L} 1$ with $\mathrm{Ni}(\mathrm{II}), \mathrm{Pd}(\mathrm{II})$, and $\mathrm{Cu}$ (II) chlorides reduced its $\beta_{\text {tot }}$ value. This is unexpected because electronic transitions involving metal-based orbitals in these complexes are supposed to reinforce their optical nonlinearities.

It is clear from the $\beta_{\text {tot }}$ values in Table 2 and the graphs in Figure 3 that the presence of a bulk solvent strengthens the first hyperpolarizability thereby reinforcing the secondorder NLO response of each molecule studied to a greater or lesser extent, depending on solvent polarity. In fact, the $\beta_{\text {tot }}$ values of these molecules when present in the nonpolar solvent (benzene) and in the polar solvents (ethanol and DMSO) are larger than the corresponding gas-phase values by factors in the ranges $2.7-13.1$ and 3.5-58.6, respectively. Exceptionally, the $\beta_{\text {tot }}$ value for the Pt(II) chloride complex in benzene dropped below the gas-phase value by a factor of about 5. Based on our $\beta_{\text {tot }}$ values, it is clear that all of the molecules investigated are likely to exhibit their greatest second-order NLO activities in DMSO, which has the largest dielectric constant among the solvents used. Consequently, further discussion pertaining to solvent effects on $\beta_{\text {tot }}$ and second-order NLO properties of MAPTSC and its complexes has been restricted to the results obtained in DMSO. As clearly shown by the graphs in Figure 3, the magnitudes of the $\beta_{\text {tot }}$ values of the molecules studied are in the order $\left[\mathrm{Pd}(\mathrm{L} 1) \mathrm{Cl}_{2}\right]<\left[\mathrm{Ni}(\mathrm{L} 1) \mathrm{Cl}_{2}\right]<\left[\mathrm{Cu}(\mathrm{L} 1) \mathrm{Cl}_{2}\right]<\mathrm{L1}<\left[\mathrm{Zn}(\mathrm{L} 1) \mathrm{Cl}_{2}\right]<$ $\left[\mathrm{Pt}(\mathrm{L} 1) \mathrm{Cl}_{2}\right]$ in vacuum and $\left[\mathrm{Pt}(\mathrm{L} 1) \mathrm{Cl}_{2}\right]<\mathrm{L} 1<\left[\mathrm{Ni}(\mathrm{L} 1) \mathrm{Cl}_{2}\right]<$ $\left[\mathrm{Zn}(\mathrm{L} 1) \mathrm{Cl}_{2}\right]<\left[\mathrm{Pd}(\mathrm{L} 1) \mathrm{Cl}_{2}\right]<\left[\mathrm{Cu}(\mathrm{L} 1) \mathrm{Cl}_{2}\right]$ in DMSO.

To determine the plausible CT mechanisms responsible for the first hyperpolarizabilities and hence quadratic NLO activities of the molecules investigated, the relationship between the frontier molecular orbitals (HOMO-LUMO) energy gaps and the $\beta_{\text {tot }}$ values has been scrutinized. Since transition metals are capable of inducing low-energy MLCT and LMCT transitions that can greatly contribute to the first 
TABLE 2: $\beta_{\mathrm{tot}}, \beta_{x}, \beta_{y}$, and $\beta_{z}$ values of MAPTSC and the complexes calculated at B3LYP/6-31++G(d,p)/(SDD for metal ions) and B3LYP/6$311++\mathrm{G}(\mathrm{d}, \mathrm{p}) /($ SDD for metal ions) levels of theory in different media.

\begin{tabular}{|c|c|c|c|c|c|c|c|c|}
\hline \multirow{2}{*}{$\begin{array}{l}\text { Basis set } \\
\text { Molecule }\end{array}$} & \multicolumn{4}{|c|}{$6-31++\mathrm{G}(\mathrm{d}, \mathrm{p}) /(\mathrm{SDD}$ for metal ions $)$} & \multicolumn{4}{|c|}{$6-311++G(d, p) /(S D D$ for metal ions $)$} \\
\hline & $\beta_{x}$ (a.u.) & $\beta_{y}$ (a.u.) & $\beta_{z}$ (a.u.) & $\beta_{\text {tot }} \times 10^{-30}(\mathrm{esu})$ & $\beta_{x}$ (a.u.) & $\beta_{y}$ (a.u.) & $\beta_{z}$ (a.u.) & $\beta_{\text {tot }} \times 10^{-30}(\mathrm{esu})$ \\
\hline \multicolumn{9}{|c|}{ Gas-phase } \\
\hline L1 & 814.59 & 198.71 & 103.02 & 7.298 & 731.74 & 184.26 & 114.38 & 6.594 \\
\hline $\mathrm{L} 2$ & 1056.16 & -724.81 & -60.49 & 11.079 & 1016.92 & -700.38 & -46.18 & 10.675 \\
\hline$\left[\mathrm{Ni}(\mathrm{L} 1) \mathrm{Cl}_{2}\right]$ & 331.18 & -506.92 & 409.83 & 6.317 & 463.27 & -528.93 & 420.36 & 7.077 \\
\hline$\left[\mathrm{Pd}(\mathrm{L} 1) \mathrm{Cl}_{2}\right]$ & 315.26 & -366.04 & 431.49 & 5.596 & 454.30 & -382.74 & 448.43 & 6.430 \\
\hline$\left[\mathrm{Pt}(\mathrm{L} 1) \mathrm{Cl}_{2}\right]$ & 1460.79 & -444.13 & 502.44 & 13.887 & 1635.25 & -452.82 & 521.00 & 15.334 \\
\hline$\left[\mathrm{Cu}(\mathrm{L} 1) \mathrm{Cl}_{2}\right]$ & -675.03 & -363.16 & 36.41 & 6.630 & -560.28 & -376.66 & 43.37 & 5.845 \\
\hline$\left[\mathrm{Zn}(\mathrm{L} 1) \mathrm{Cl}_{2}\right]$ & -811.24 & -390.90 & 345.28 & 8.332 & -706.61 & -389.50 & 361.74 & 7.639 \\
\hline \multicolumn{9}{|c|}{ Benzene } \\
\hline L1 & 1282.49 & 56.10 & 167.35 & 11.184 & 1179.22 & 45.43 & 174.07 & 10.306 \\
\hline $\mathrm{L} 2$ & 1551.36 & -1089.99 & -89.36 & 16.398 & 1502.70 & -1060.86 & -70.78 & 15.903 \\
\hline$\left[\mathrm{Ni}(\mathrm{L} 1) \mathrm{Cl}_{2}\right]$ & -823.01 & -357.05 & 543.42 & 9.062 & -666.92 & -391.48 & 557.98 & 8.239 \\
\hline$\left[\mathrm{Pd}(\mathrm{L} 1) \mathrm{Cl}_{2}\right]$ & 939.71 & -327.52 & -637.52 & 10.210 & 773.32 & -357.51 & -660.79 & 9.315 \\
\hline$\left[\mathrm{Pt}(\mathrm{L} 1) \mathrm{Cl}_{2}\right]$ & -573.09 & -407.87 & -744.78 & 8.850 & -785.46 & -425.23 & -769.99 & 10.188 \\
\hline$\left[\mathrm{Cu}(\mathrm{L} 1) \mathrm{Cl}_{2}\right]$ & -2260.96 & -238.64 & 184.96 & 19.706 & -2117.62 & -256.13 & 197.51 & 18.507 \\
\hline \multicolumn{9}{|c|}{ Ethanol } \\
\hline $\mathrm{L} 1$ & 2137.32 & -269.15 & 147.01 & 18.654 & 2024.98 & -291.42 & 158.79 & 17.728 \\
\hline L2 & 2267.08 & -1677.29 & -143.98 & 24.395 & 2205.02 & -1645.93 & -119.16 & 23.794 \\
\hline$\left[\mathrm{Ni}(\mathrm{L1}) \mathrm{Cl}_{2}\right]$ & -3142.76 & -179.82 & 920.82 & 28.335 & -2956.62 & -233.21 & 947.43 & 26.898 \\
\hline$\left[\mathrm{Pd}(\mathrm{L} 1) \mathrm{Cl}_{2}\right]$ & 3594.07 & -415.42 & -1047.59 & 32.541 & 3379.29 & -475.21 & -1083.34 & 30.932 \\
\hline$\left[\mathrm{Pt}(\mathrm{L} 1) \mathrm{Cl}_{2}\right]$ & 1657.19 & -276.44 & -1112.58 & 17.409 & 1397.74 & -309.05 & -1150.21 & 15.865 \\
\hline$\left[\mathrm{Cu}(\mathrm{L1}) \mathrm{Cl}_{2}\right]$ & -7509.45 & -198.28 & 712.29 & 65.190 & -7206.75 & -225.86 & 739.63 & 62.619 \\
\hline$\left[\mathrm{Zn}(\mathrm{L1}) \mathrm{Cl}_{2}\right]$ & -3310.72 & -198.42 & 547.88 & $\begin{array}{l}29.042 \\
D M S O\end{array}$ & -3182.29 & -203.79 & 582.65 & 28.005 \\
\hline L1 & 2206.37 & -303.91 & 144.37 & 19.282 & 2094.06 & -325.95 & 156.44 & 18.359 \\
\hline $\mathrm{L} 2$ & 2315.01 & -1719.20 & -147.47 & 24.945 & 2251.91 & -1687.90 & -122.31 & 24.336 \\
\hline$\left[\mathrm{Ni}(\mathrm{L1}) \mathrm{Cl}_{2}\right]$ & -3329.44 & -163.94 & 955.14 & 29.958 & -3140.90 & -219.30 & 982.93 & 28.496 \\
\hline$\left[\mathrm{Pd}(\mathrm{L} 1) \mathrm{Cl}_{2}\right]$ & -3565.27 & -417.46 & 935.93 & 32.049 & -3351.90 & -483.07 & 969.63 & 30.433 \\
\hline$\left[\mathrm{Pt}(\mathrm{L} 1) \mathrm{Cl}_{2}\right]$ & 1848.88 & -258.57 & -1142.88 & 18.911 & 1585.59 & -292.58 & -1181.51 & 17.269 \\
\hline$\left[\mathrm{Cu}(\mathrm{L} 1) \mathrm{Cl}_{2}\right]$ & -8098.75 & -202.43 & 757.49 & 70.295 & -7773.97 & -230.92 & 783.55 & 67.531 \\
\hline$\left[\mathrm{Zn}(\mathrm{L} 1) \mathrm{Cl}_{2}\right]$ & -3437.58 & -176.12 & 553.46 & 30.119 & -3308.23 & -181.74 & 588.93 & 29.073 \\
\hline
\end{tabular}

hyperpolarizability of MAPTSC, photoinduced electronic transitions in the molecules have been studied via the TDDFT method. Changes in the gas-phase $\beta_{\text {tot }}$ value for L1 as a result of $\mathrm{L1}-\mathrm{MCl}_{2}$ binding are attributed solely to the effects of the different transition metal ions present in the $\mathrm{MCl}_{2}$ fragment. Such changes in the presence of both the $\mathrm{MCl}_{2}$ fragment and the bulk solvent are attributable to the concomitant effects of metallation and solvent polarity.

3.3. First Molecular Hyperpolarizabilities and HOMO-LUMO Energy Analysis. The HOMO-LUMO energy gaps $\left(\Delta E_{\mathrm{H}-\mathrm{L}}\right)$ of $\mathrm{L} 1$ and its transition metal chloride complexes, computed at B3LYP/6-31++G(d,p)/(SDD for metal ions) level of theory in gas-phase and in DMSO are listed in Table 3. The $\Delta E_{\mathrm{H}-\mathrm{L}}$ values for the $\mathrm{Cu}(\mathrm{II})$ chloride complex of $\mathrm{L} 1$ in both media have been calculated from the eigenvalues of the beta spin orbitals, because a majority of its electronic transitions (analyzed in the next section) involve these orbitals. The D- $\pi$-A or push-pull CT mechanism predominates in molecules when an inverse proportionality relationship exists between their $\Delta E_{\mathrm{H}-\mathrm{L}}$ and $\beta_{\text {tot }}$ values. The push-pull mechanism is strongly dependent on HOMO-LUMO energy gaps because a proper electronic conjugation must exist among the molecular orbitals of a system for ICT to be effective [7]. The relationship between the gas-phase $\Delta E_{\mathrm{H}-\mathrm{L}}$ and $\beta_{\text {tot }}$ values of the molecules studied is far from being inversely proportional, implying that the $\mathrm{D}-\pi$-A push-pull process is not the dominant CT mechanism in each of the molecules in gas-phase. Photoinduced electronic transitions with CT character (involving metal-based orbitals) are certainly playing the dominant role. 
TABLE 3: HOMO/LUMO energies and $\beta_{\text {tot }}$ values of MAPTSC and its metal chloride complexes computed in gas-phase and DMSO at B3LYP/6-31++G(d,p)/(SDD for metal ions) level of theory.

\begin{tabular}{|c|c|c|c|c|c|c|c|c|}
\hline \multirow{2}{*}{ Molecule } & \multicolumn{3}{|c|}{ Energies in gas-phase $(\mathrm{eV})$} & \multirow{2}{*}{$\beta_{\text {tot }} \times 10^{-30}(\mathrm{esu})$} & \multicolumn{3}{|c|}{ Energies in DMSO $(\mathrm{eV})$} & \multirow{2}{*}{$\beta_{\text {tot }} \times 10^{-30}(\mathrm{esu})$} \\
\hline & $\begin{array}{r}\mathrm{HOMO}^{\mathrm{a}} \\
\text { energy }\end{array}$ & $\begin{array}{l}\text { LUMO }^{\mathrm{b}} \\
\text { energy }\end{array}$ & $\Delta E_{\mathrm{H}-\mathrm{L}}^{\mathrm{c}}$ & & $\begin{array}{c}\mathrm{HOMO}^{\mathrm{a}} \\
\text { energy }\end{array}$ & $\begin{array}{c}\text { LUMO }^{\mathrm{b}} \\
\text { energy }\end{array}$ & $\Delta E_{\mathrm{H}-\mathrm{L}}^{\mathrm{c}}$ & \\
\hline $\mathrm{L} 1$ & -5.481 & -1.189 & 4.292 & 7.298 & -6.134 & -1.334 & 4.801 & 19.282 \\
\hline$\left[\mathrm{Ni}(\mathrm{L} 1) \mathrm{Cl}_{2}\right]$ & -5.815 & -2.397 & 3.418 & 6.317 & -6.589 & -2.797 & 3.791 & 29.958 \\
\hline$\left[\mathrm{Pd}(\mathrm{L} 1) \mathrm{Cl}_{2}\right]$ & -5.895 & -2.496 & 3.399 & 5.596 & -6.574 & -3.010 & 3.564 & 32.049 \\
\hline$\left[\mathrm{Pt}(\mathrm{L1}) \mathrm{Cl}_{2}\right]$ & -5.715 & -2.386 & 3.329 & 13.887 & -6.272 & -2.350 & 3.923 & 18.911 \\
\hline$\left[\mathrm{Cu}(\mathrm{L} 1) \mathrm{Cl}_{2}\right]$ & -6.240 & -3.575 & 2.665 & 6.630 & -6.723 & -4.043 & 2.679 & 70.295 \\
\hline$\left[\mathrm{Zn}(\mathrm{L} 1) \mathrm{Cl}_{2}\right]$ & -6.744 & -2.193 & 4.551 & 8.332 & -6.621 & -2.014 & 4.607 & 30.119 \\
\hline
\end{tabular}

${ }^{a} \mathrm{HOMO}$ stands for highest occupied molecular orbital.

${ }^{\mathrm{b}}$ LUMO stands for lowest unoccupied molecular orbital.

${ }^{c} \Delta E_{\mathrm{H}-\mathrm{L}}$ represents HOMO-LUMO energy gap.

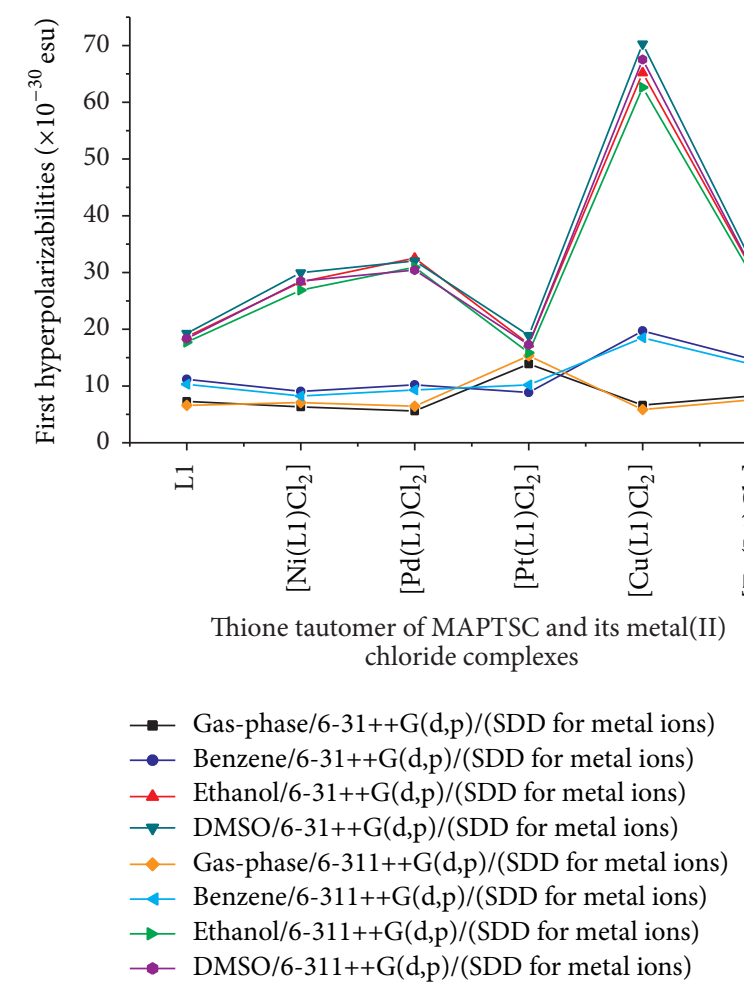

Figure 3: Trends in $\beta_{\text {tot }}$ values of L1 and its transition metal chloride complexes from gas to solvent phases.

In DMSO, a somewhat inverse proportionality relationship is found between the values of $\Delta E_{\mathrm{H}-\mathrm{L}}$ and $\beta_{\mathrm{tot}}$, suggesting that CT in these molecules is due to the combined effects of photoinduced electronic transitions with CT character and the D- $\pi$-A push-pull process. The polar solvent medium therefore enhances charge transfer in each of the molecules investigated.

3.4. Electronic Absorption Spectra of L1 and Its Transition Metal Chloride Complexes. In order to determine the optical transparency of each investigated molecule in the visible region of the EM spectrum and to determine the electronic transitions with CT character, the UV-Vis spectra of these molecules were simulated via TD-DFT studies. To study solvatochromic effects, the UV-Vis spectra were calculated in both gas-phase and DMSO. For each molecule, electronic transitions to the first 10 low-lying singlet excited states were studied at CAM-B3LYP/6-31++G(d,p)/(SDD for metal ions) level of theory. The computed electronic excitation energies ( $\Delta E$ in $\mathrm{eV}$ ), wavelengths ( $\lambda$ in $\mathrm{nm}$ ), and oscillator strengths $(f)$ are presented in Table 4 . The electronic transitions with oscillator strengths 0.02 and above have been considered, since those with very low oscillator strengths are likely to make insignificant contributions to the first hyperpolarizabilities of the molecules studied. The UV-Vis spectra of these molecules in gas and solvent phases are presented in Figure 4.

The modification undergone by the $\beta_{\text {tot }}$ value for L1 upon complexation with different transition metal chlorides appears to be related to the types and intensities (oscillator strengths) of the electronic excitations in the complexes formed. The reduction in the $\beta_{\text {tot }}$ value for L1 following its complexation with $\mathrm{Ni}(\mathrm{II}), \mathrm{Pd}(\mathrm{II})$, and $\mathrm{Cu}(\mathrm{II})$ chlorides in vacuo is apparently linked to the reduction in the number of electronic transitions in the resulting complexes, coupled with a decrease in the oscillator strengths of the transitions. Although complexation leads to a slight lowering of the electronic excitation energies of the dominant electronic transitions in the complexes $\left[\mathrm{Ni}(\mathrm{Ll}) \mathrm{Cl}_{2}\right],\left[\mathrm{Pd}(\mathrm{L1}) \mathrm{Cl}_{2}\right]$, and $\left[\mathrm{Cu}(\mathrm{L} 1) \mathrm{Cl}_{2}\right]$, a corresponding increase in their $\beta_{\text {tot }}$ values is not observed. This is probably due to the significant intensity reduction of these transitions relative to those in L1. On the contrary, the complexation of L1 with the Pt(II) chloride in vacuum results in a dramatic increment of the ligand's gasphase $\beta_{\text {tot }}$ value, which can be attributed to the introduction of several low-energy intense electronic transitions.

By inspection of Figure 4 and Table 4, it can be seen that the number of reasonably strong electronic transitions in the molecules studied increases significantly in DMSO. Moreover, the polar DMSO medium leads to a modest lowering of the excitation energies of the dominant electronic transitions in all complexes investigated, except the $\mathrm{Pt}(\mathrm{II})$ chloride complex. Therefore, the $\left[\mathrm{Ni}(\mathrm{L} 1) \mathrm{Cl}_{2}\right],\left[\mathrm{Pd}(\mathrm{L} 1) \mathrm{Cl}_{2}\right],\left[\mathrm{Cu}(\mathrm{L} 1) \mathrm{Cl}_{2}\right]$, 


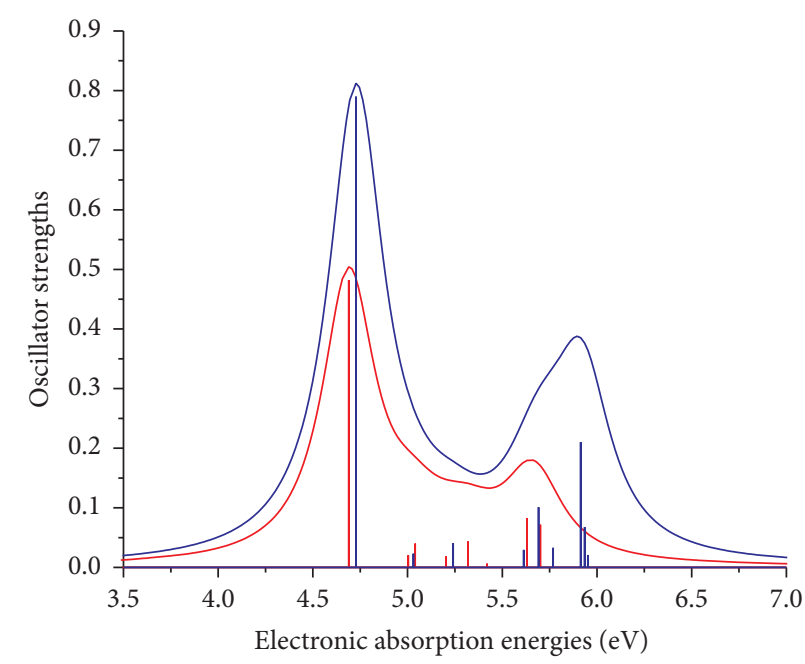

L1

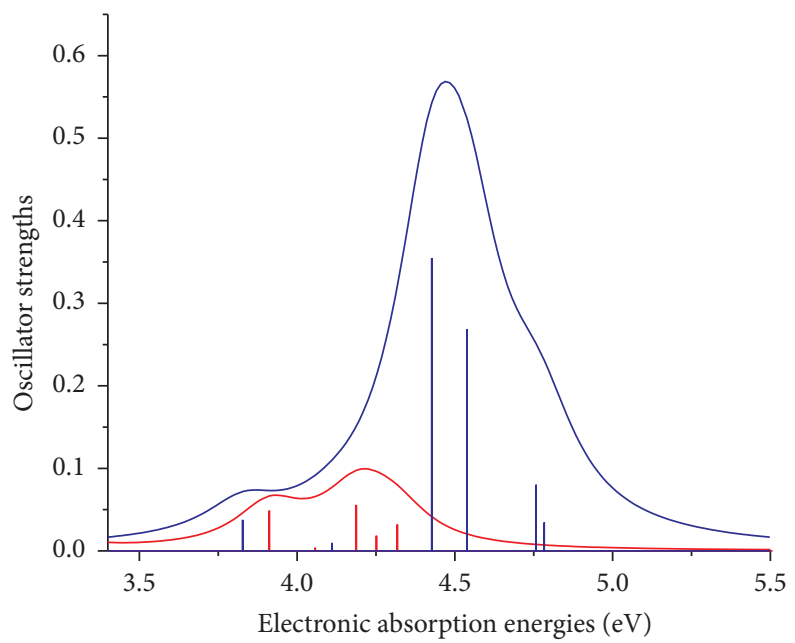

$\left[\mathrm{Pd}(\mathrm{L} 1) \mathrm{Cl}_{2}\right]$

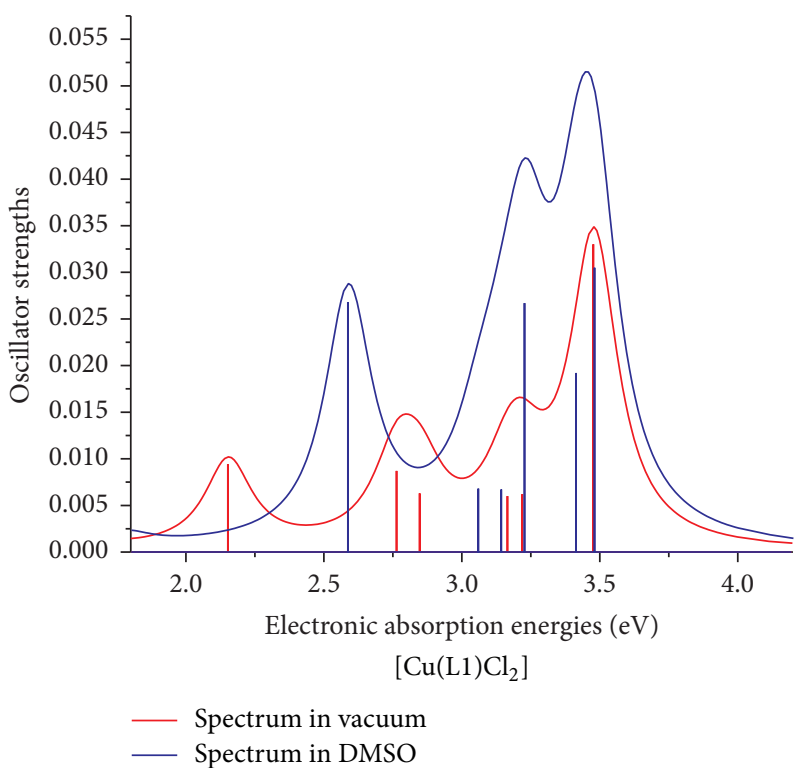

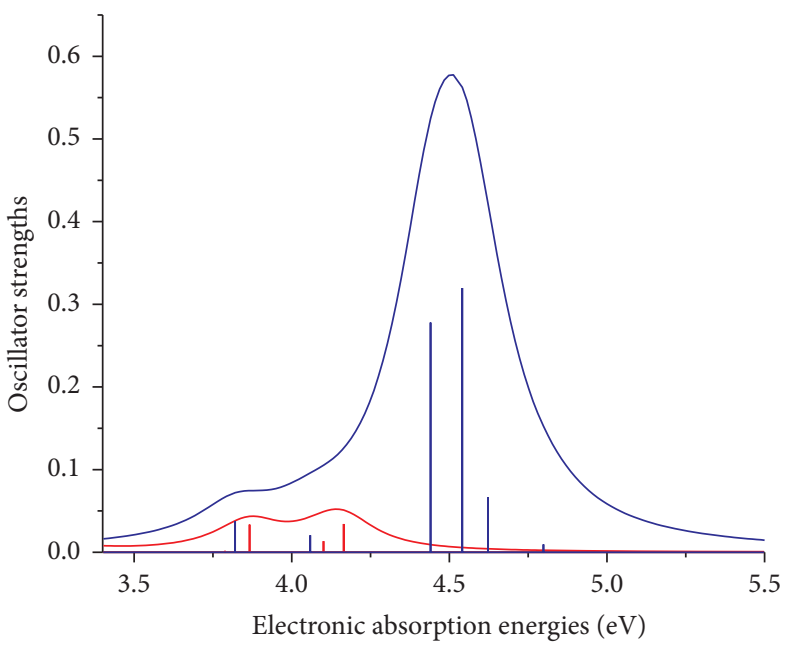

$\left[\mathrm{Ni}(\mathrm{L} 1) \mathrm{Cl}_{2}\right]$
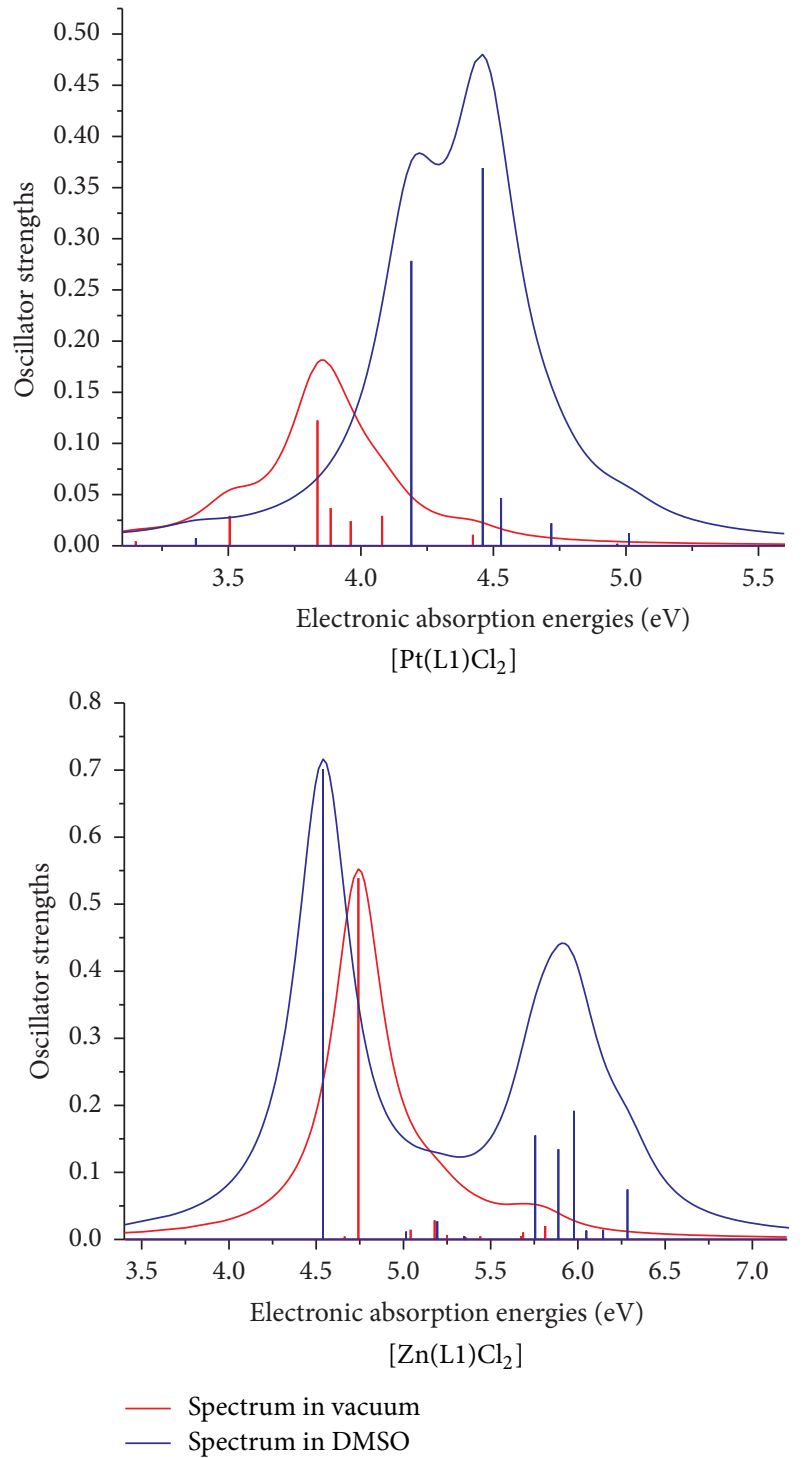

FIGURE 4: The electronic absorption spectra of $\mathrm{L} 1$ and its complexes in gas-phase and DMSO computed at CAM-B3LYP/6-31++G(d,p)/(SDD for metal ions) level of theory. 
TABLE 4: Absorption energies $(E, \mathrm{eV})$, wavelengths $(\lambda, \mathrm{nm})$, and oscillator strengths $(f)$ of $\mathrm{L} 1$ and the complexes, calculated at CAM-B3LYP/6$31++\mathrm{G}(\mathrm{d}, \mathrm{p}) /(\mathrm{SDD}$ for metal ions) level of theory in gas-phase and DMSO by the TD-DFT method.

\begin{tabular}{|c|c|c|c|c|c|c|c|c|}
\hline \multirow{2}{*}{ Molecule } & \multicolumn{4}{|c|}{ Gas-phase } & \multicolumn{4}{|c|}{ DMSO } \\
\hline & State & $\Delta E(\mathrm{eV})$ & $\lambda(\mathrm{nm})$ & $f$ & State & $\Delta E(\mathrm{eV})$ & $\lambda(\mathrm{nm})$ & $f$ \\
\hline \multirow{9}{*}{ L1 } & S2 & 4.6892 & 264.40 & 0.4821 & S2 & 4.7279 & 262.24 & 0.7898 \\
\hline & S3 & 5.0039 & 247.77 & 0.0203 & S3 & 5.0309 & 246.44 & 0.0231 \\
\hline & S4 & 5.0404 & 245.98 & 0.0401 & S4 & 5.2409 & 236.57 & 0.0406 \\
\hline & S6 & 5.3192 & 233.09 & 0.0435 & S5 & 5.6131 & 220.88 & 0.0294 \\
\hline & S8 & 5.6300 & 220.22 & 0.0826 & S6 & 5.6917 & 217.83 & 0.1009 \\
\hline & S10 & 5.7011 & 217.47 & 0.0717 & S7 & 5.7689 & 214.92 & 0.0329 \\
\hline & & & & & S8 & 5.9143 & 209.63 & 0.2104 \\
\hline & & & & & S9 & 5.9352 & 208.90 & 0.0676 \\
\hline & & & & & S10 & 5.9525 & 208.29 & 0.0210 \\
\hline \multirow{5}{*}[\mathrm{Ni}(\mathrm{L}1)\mathrm{Cl}_{2}]{} & S7 & 3.8661 & 320.70 & 0.0336 & S5 & 3.8202 & 324.55 & 0.0377 \\
\hline & S9 & 4.1644 & 297.73 & 0.0342 & S6 & 4.0588 & 305.47 & 0.0206 \\
\hline & & & & & S7 & 4.4403 & 279.23 & 0.2780 \\
\hline & & & & & S8 & 4.5408 & 273.04 & 0.3197 \\
\hline & & & & & S9 & 4.6220 & 268.25 & 0.0666 \\
\hline \multirow{5}{*}[\mathrm{Pd}(\mathrm{L}1)\mathrm{Cl}_{2}]{} & S6 & 3.9119 & 316.94 & 0.0488 & S5 & 3.8273 & 323.95 & 0.0376 \\
\hline & S8 & 4.1873 & 296.10 & 0.0557 & S7 & 4.4265 & 280.10 & 0.3549 \\
\hline & S10 & 4.3174 & 287.17 & 0.0320 & S8 & 4.5383 & 273.20 & 0.2687 \\
\hline & & & & & S9 & 4.7574 & 260.61 & 0.0802 \\
\hline & & & & & S10 & 4.7830 & 259.22 & 0.0345 \\
\hline \multirow{5}{*}[\mathrm{Pt}(\mathrm{L}1)\mathrm{Cl}_{2}]{} & S5 & 3.5049 & 353.75 & 0.0293 & S5 & 4.1907 & 295.85 & 0.2784 \\
\hline & S6 & 3.8361 & 323.20 & 0.1224 & S6 & 4.4592 & 278.04 & 0.3691 \\
\hline & S7 & 3.8860 & 319.05 & 0.0368 & S7 & 4.5295 & 273.72 & 0.0466 \\
\hline & S8 & 3.9611 & 313.00 & 0.0243 & S8 & 4.7188 & 262.75 & 0.0219 \\
\hline & S9 & 4.0806 & 303.84 & 0.0292 & & & & \\
\hline \multirow{3}{*}[\mathrm{Cu}(\mathrm{L}1)\mathrm{Cl}_{2}]{} & S10 & 3.4788 & 356.40 & 0.0330 & S5 & 2.5892 & 478.86 & 0.0268 \\
\hline & & & & & S8 & 3.2291 & 383.96 & 0.0267 \\
\hline & & & & & S10 & 3.4829 & 355.98 & 0.0305 \\
\hline \multirow{6}{*}[\mathrm{Zn}(\mathrm{L}1)\mathrm{Cl}_{2}]{} & S2 & 4.7424 & 261.44 & 0.5390 & S1 & 4.5399 & 273.10 & 0.7015 \\
\hline & $\mathrm{S} 4$ & 5.1784 & 239.43 & 0.0285 & S3 & 5.1949 & 238.67 & 0.0271 \\
\hline & S10 & 5.8132 & 213.28 & 0.0202 & S5 & 5.7561 & 215.39 & 0.1552 \\
\hline & & & & & S6 & 5.8884 & 210.56 & 0.1346 \\
\hline & & & & & S7 & 5.9773 & 207.43 & 0.1919 \\
\hline & & & & & $\mathrm{S} 10$ & 6.2838 & 197.31 & 0.0746 \\
\hline
\end{tabular}

and $\left[\mathrm{Zn}(\mathrm{L} 1) \mathrm{Cl}_{2}\right]$ complexes must possess highly polar excited states that are greatly solvated and stabilized by the polar DMSO molecules, whereas their ground states are less polar and hence less stabilized by solvation. Consequently, excitation energies from the less stabilized ground states to the highly stabilized excited states are reduced, leading to an increase in the number of intense electronic excitations in the complexes. This in turn causes a dramatic increment in the $\beta_{\text {tot }}$ values of the complexes in DMSO as solvent, thus enhancing their quadratic NLO responses. Strong absorption of light in the visible region of the EM spectrum restricts the NLO applications of materials [39] due to significant transparency/nonlinearity trade-offs that often lead to lower device efficiency and reduced photostability. From Figure 4, it can be seen that, apart from the $\left[\mathrm{Cu}(\mathrm{L1}) \mathrm{Cl}_{2}\right]$ complex, all investigated molecules have high optical transparencies in the entire visible region, implying that they suffer very low optical losses. Hence, transparency/nonlinearity tradeoffs are highly minimized in $\mathrm{Ll}$ and its $\mathrm{Ni}(\mathrm{II}), \mathrm{Pd}(\mathrm{II}), \mathrm{Pt}(\mathrm{II})$, and $\mathrm{Zn}$ (II) chloride complexes, confirming their suitability for the fabrication of NLO devices.

To decipher the relationship between solvent polarity and the first hyperpolarizabilities of the molecules studied, their UV-Vis spectra in gas-phase and in DMSO have been compared as shown in Figure 4. It is clear from Figure 3 that polar solvents substantially increase the $\beta_{\text {tot }}$ value for the $\mathrm{Cu}$ (II) chloride complex of L1 but have almost no effect on the $\beta_{\text {tot }}$ value for the $\mathrm{Pt}(\mathrm{II})$ chloride complex. The effects of the polar solvents on the $\beta_{\text {tot }}$ values for these molecules have been explained in terms of the solvatochromic shift directions of their strongest electronic transitions on going from the gas-phase to the DMSO solvent medium, as elucidated in 
Figure 4. The drastic increment in the $\beta_{\text {tot }}$ value for the $\mathrm{Cu}(\mathrm{II})$ chloride complex in DMSO is ascribed to its positive solvatochromism (the shift of its strongest CT absorption bands towards lower excitation energies and longer wavelengths). The remarkable negative solvatochromism exhibited by the $\mathrm{Pt}$ (II) chloride complex in DMSO (the shift of its strongest CT absorption bands towards higher excitation energies and shorter wavelengths) accounts for the insignificant modification of its $\beta_{\text {tot }}$ value in the polar solvents. The positive solvatochromism (bathochromic or red-shift of the strongest CT absorption bands) exhibited by the $\left[\mathrm{Zn}(\mathrm{L1}) \mathrm{Cl}_{2}\right]$ complex is responsible for the increment in its $\beta_{\text {tot }}$ value in DMSO. Solvatochromism as such is not obvious from the comparison of the gas and solvent phase UV-Vis spectra of L1 in Figure 4. The increment in its $\beta_{\text {tot }}$ value in DMSO is certainly linked to the increase in the intensities of its strong electronic excitations. Although the complexes $\left[\mathrm{Ni}(\mathrm{L} 1) \mathrm{Cl}_{2}\right]$ and $\left[\mathrm{Pd}(\mathrm{L} 1) \mathrm{Cl}_{2}\right]$ display a certain degree of negative solvatochromism in DMSO (hypsochromic or blue-shift of their strongest CT absorption bands), appreciable increments in their $\beta_{\text {tot }}$ values are observed due to significant contributions from strong low-lying electronic transitions of CT character to their first hyperpolarizabilities.

By comparing the gas-phase UV-Vis absorption spectra of ligand L1 with those of its metal chloride complexes, it is clear that metallation results in significant modifications of the ligand's electronic absorption spectrum. These modifications are caused by the introduction of CT bands induced by the promotion of electrons from orbitals that are predominantly metal in character to orbitals that are predominantly ligand in character (MLCT), or the reverse (LMCT). These CT bands generally give significant contributions to the first molecular hyperpolarizability. Such CT transitions are absent from the UV-Vis spectrum of the $\mathrm{Zn}$ (II) chloride complex because the $d$-orbitals of the $\mathrm{Zn}$ (II) ion are fully filled and do not participate in electronic transitions.

The dominant electronic transitions of the molecules studied (those with the greatest oscillator strengths) have been characterized via natural transition orbital (NTO) analysis which generates unique "particle-hole" NTO pairs from the canonical molecular orbitals. Only the dominant electronic transitions (those boldly highlighted in Table 4) have been characterized because they are capable of remarkable contributions to the first molecular hyperpolarizability. For each "particle-hole" NTO pair, the "particle" shows where in the system electrons come from and the "hole" indicates where the electrons go to, during electronic transitions. The NTOs of the molecules studied (shown in Table 5) were computed using Gaussian 09W and then rendered with VMD 1.9.2 [40] using isosurface cube files generated by Multiwfn 3.3.8. To obtain a quantitative description of the NTOs, orbital contributions from different molecular fragments (reported in Table 6) were calculated using the orbital composition analysis option [41] of Multiwfn 3.3.8. These orbital compositions, together with the electronic distributions of the NTOs (depicted by their isosurfaces in Table 5) were exploited in characterizing the dominant electronic transitions of the molecules studied. These transitions along with their most probable characters are listed in Table 7.
The qualitative and quantitative analyses of the NTOs have revealed photoinduced electronic transitions with CT character in the UV-Vis spectra of the molecules. In gasphase, the "particle" of L1 is predominantly contributed by lone pair orbitals $(n)$ located on the sulfur and nitrogen atoms in the TSC moiety, while the corresponding "hole" is fairly distributed over the entire molecule and is dominated by $\pi^{*}$-antibonding character. This implies that $n \rightarrow \pi^{*}$ electronic transitions predominate in the gas-phase ligand. The "particle" and "hole" of L1 in DMSO are both distributed over the entire molecular framework. While the "particle" is comprised of $n$ and $\pi$-type orbitals, the "hole" is dominated by $\pi^{*}$-type orbitals. Therefore, both $n \rightarrow \pi^{*}$ and $\pi \rightarrow \pi^{*}$ electronic transitions are possible in the ligand when present in DMSO as solvent. The DMSO environment thus enhances CT in L1 giving rise to the dramatic increment of its $\beta_{\text {tot }}$ value. The complexation of $\mathrm{L} 1$ with different transition metal chlorides introduces new electronic transitions with CT character in the electronic spectrum of L1 and/or modifies the existing ones, owing to the presence of low-lying metal-based orbitals. It is evidenced in Tables 5 and 7 that the dominant electronic transitions in the metal chlorides complexes of L1 studied (except the $\mathrm{Zn}$ (II) chloride complex) are dominated by MLCT and/or LMCT electronic transitions, along with LLCT transitions. The introduction of MLCT and LMCT electronic transitions often, but not always, bolsters the first molecular hyperpolarizabilities of organic push-pull systems, as observed in the present study. From the foregoing, the NLO response of MAPTSC can be highly tuned by transition metal chelation.

The complexation of L1 with the Ni(II), Pd(II), Pt(II), and $\mathrm{Cu}$ (II) chlorides in vacuo leads to "partial resonance" or loss of conjugation in the benzene rings of the "particle" NTOs of the resulting complexes (see Table 5). Consequently, ICT in these complexes derived from donor-acceptor electron cloud movement across the $\pi$-conjugated pathway is disrupted in vacuo. As such, the D- $\pi$-A or push-pull CT process is unlikely to occur in the gas-phase complexes. Nevertheless, the electronic transitions with CT character MLCT, LMCT, and LLCT do occur in these complexes accounting for their first hyperpolarizabilities. The scenario in the gas-phase $\mathrm{Zn}$ (II) chloride complex is opposite to that in the aforementioned complexes because $\pi$-conjugation is rather reinforced in the benzene rings of both the "particle" and the "hole," whereas MLCT, LMCT, and LLCT electronic transitions are prohibited. This implies that CT in this complex is almost entirely due to the push-pull mechanism. The absence of the metal-based transitions MLCT and LMCT from the UVVis spectrum of the $\left[\mathrm{Zn}(\mathrm{L} 1) \mathrm{Cl}_{2}\right]$ complex is attributed to the nonparticipation of the fully filled $d$-orbitals of the $\mathrm{Zn}$ (II) ion in electronic transitions. It is clear from the isosurfaces in Table 5 that $\pi$-conjugation is unhindered in the benzene rings of the "particle" NTOs of the complexes when present in the DMSO solvent medium. This significantly strengthens their push-pull CT mechanisms, resulting in dramatic first hyperpolarizability increments. It is found that as solvent polarity increases, ICT in the $\mathrm{Ni}(\mathrm{II}), \mathrm{Pd}(\mathrm{II}), \mathrm{Pt}(\mathrm{II})$, and $\mathrm{Cu}(\mathrm{II})$ chlorides complexes of L1 increases, and their first hyperpolarizabilities are increasingly contributed by a synergy of 
TABLE 5: The dominant NTO "particle-hole" pairs for the dominant electronic transitions of each investigated molecule in gas-phase and in DMSO.

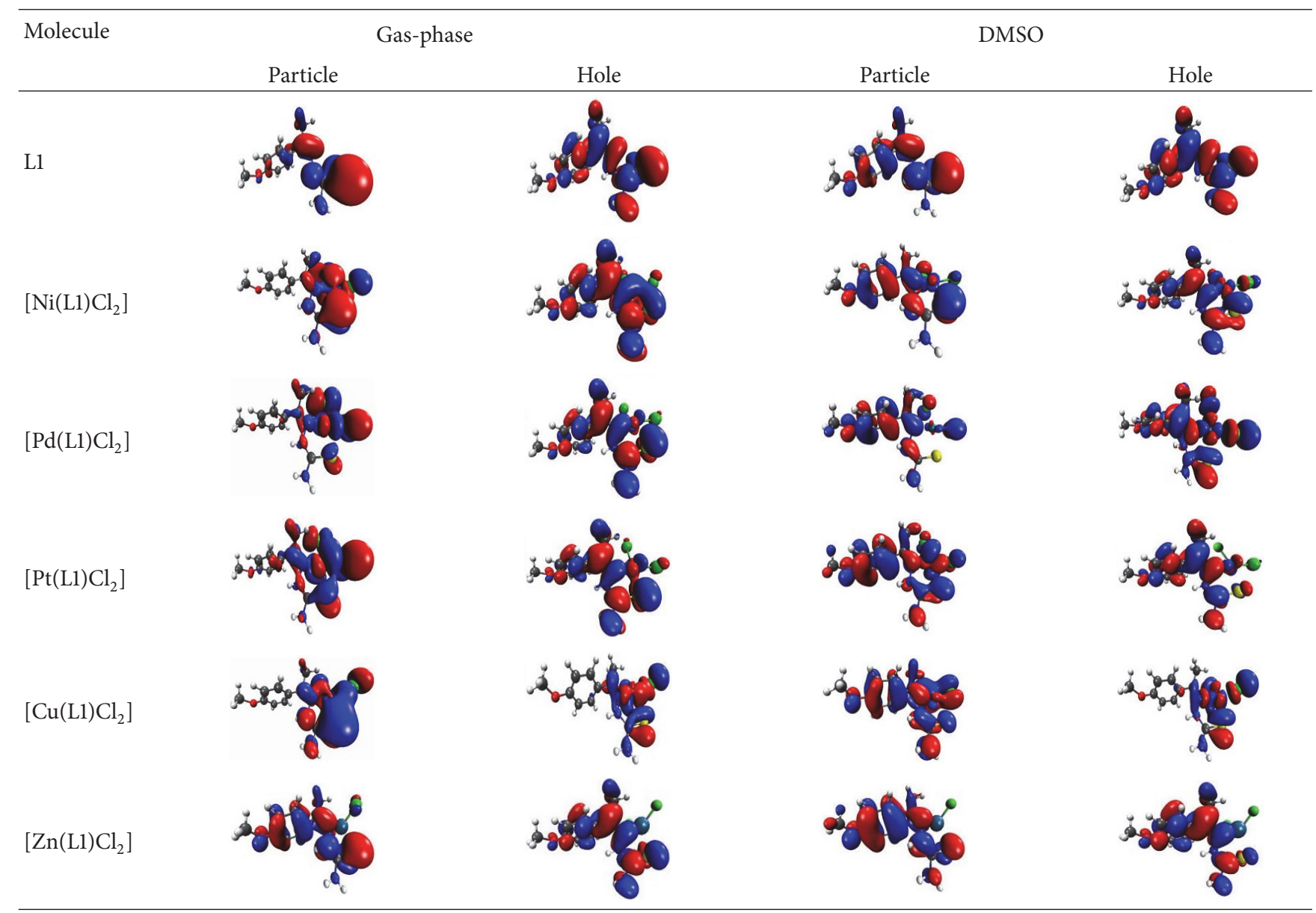

electronic transitions with CT character (MLCT, LMCT, and LLCT) and the donor-acceptor electron cloud movements across intervening $\pi$-conjugation paths. Exceptionally, ICT in the $\mathrm{Zn}$ (II) chloride complex is found to occur entirely via the push-pull mechanism in both gas and solvent phases.

3.5. Natural Bond Orbital (NBO) Analysis. To gain a deeper insight into the nature of conjugative and hyperconjugative interactions responsible for electron delocalization and ICT in $\mathrm{L} 1$ and its complexes, natural bond orbital (NBO) analyses have been carried out on the molecules studied using the NBO 3.1 [42] module embedded in Gaussian 09W. The NBO results are presented in Tables 8 and 9. The delocalization of electron density (ED) between occupied Lewis-type (bonding or lone pair) natural bond orbitals (NBOs) and formally unoccupied non-Lewis NBOs (antibonds or Rydberg) correspond to stabilizing donor-acceptor interactions. The stabilization energy, $E^{(2)}$, that results from the interaction of a donor $(i)$ and an acceptor $(j)$ NBO pair is estimated by means of the second-order perturbation theory as shown in (5). The values of $E^{(2)}$ are proportional to the extent of conjugation. Hence, the larger the $E^{(2)}$ value, the more intensive the donor-acceptor NBO interaction and the larger the ICT that occurs in the entire system [23, 43].

$$
E_{i j}^{(2)}=-q \frac{\left(\widehat{F}_{i j}\right)^{2}}{\varepsilon_{j}-\varepsilon_{i}},
$$

where $q$ is the donor orbital occupancy, $\varepsilon_{i}$ and $\varepsilon_{j}$ are diagonal elements (orbital energies) of donor and acceptor NBOs, respectively, and $\widehat{F}_{i j}$ is the off-diagonal NBO Fock matrix element. In molecular systems, $\pi$-conjugation results from $\pi$ electron delocalization due to $\pi \rightarrow \pi^{*}$ interactions. While primary hyperconjugation is due to $\sigma \rightarrow \pi^{*}, n \rightarrow \pi^{*}, n \rightarrow$ $\sigma^{*}$, or $\pi^{*} \rightarrow \pi^{*}$ interactions, secondary hyperconjugation occurs as a result of $\sigma \rightarrow \sigma^{*}$ interactions [11]. The NBO interactions $\mathrm{LP}(2) \mathrm{O} 2 \rightarrow \pi^{*}(\mathrm{C} 6-\mathrm{C} 7), \mathrm{LP}(1) \mathrm{O} 2 \rightarrow \pi^{*}$ (C6-C11), or $\mathrm{LP}(2) \mathrm{O} 2 \rightarrow \mathrm{LP}^{*}(1) \mathrm{C} 6$, with $E^{(2)}$ values in the range 16.04$59.60 \mathrm{kcal} / \mathrm{mol}$ have clearly confirmed that the $-\mathrm{OCH}_{3}$ group is the electron donor in all of the D- $\pi$-A or push-pull systems studied. Intensive $\pi \rightarrow \pi^{*}$ conjugative interactions dominate in the benzene rings of all molecules studied, greatly enhancing their CT capabilities and optical nonlinearities. The $\pi$-conjugated pathway for the $D-\pi$-A structure of each 
TABLE 6: Natural transition orbitals (NTOs) compositions for the thione tautomer of MAPTSC and its complexesin gas-phase and DMSO, calculated at the TD-DFT/CAM-B3LYP/6-31++G(d,p)/(SDD for metal ions) level of theory.

\begin{tabular}{|c|c|c|c|c|c|c|}
\hline \multirow{2}{*}{ Molecule } & \multirow{2}{*}{ NTOs } & \multicolumn{4}{|c|}{ Orbital compositions of fragments (\%) } & \multirow{2}{*}{ Main distribution of NTOs on molecular systems } \\
\hline & & $\mathrm{M}(\mathrm{II})^{\mathrm{a}}$ & MAP $^{\mathrm{b}}$ & TSC $^{\mathrm{c}}$ & $2 \mathrm{Cl}^{-}$ & \\
\hline \multicolumn{7}{|c|}{ Gas-phase } \\
\hline \multirow{2}{*}{$\mathrm{L} 1$} & Hole & - & 36.496 & 63.504 & - & $\mathrm{MAP}+\mathrm{TSC}$ \\
\hline & Particle & - & 13.856 & 86.144 & - & TSC \\
\hline \multirow{2}{*}[\mathrm{Ni}(\mathrm{L}1)\mathrm{Cl}_{2}]{} & Hole & 4.537 & 50.724 & 43.388 & 1.351 & $\mathrm{MAP}+\mathrm{TSC}$ \\
\hline & Particle & 46.092 & 2.627 & 9.700 & 41.581 & $\mathrm{Ni}(\mathrm{II})$ ion $+2 \mathrm{Cl}^{-}$ \\
\hline \multirow{2}{*}[\mathrm{Pd}(\mathrm{L}1)\mathrm{Cl}_{2}]{} & Hole & 3.958 & 49.695 & 45.108 & 1.239 & $\mathrm{MAP}+\mathrm{TSC}$ \\
\hline & Particle & 32.732 & 4.901 & 6.195 & 56.172 & $\mathrm{Pd}(\mathrm{II})$ ion $+2 \mathrm{Cl}^{-}$ \\
\hline \multirow{2}{*}[\mathrm{Pt}(\mathrm{L}1)\mathrm{Cl}_{2}]{} & Hole & 5.517 & 43.596 & 49.385 & 1.501 & MAP + TSC \\
\hline & Particle & 56.516 & 5.890 & 7.933 & 29.661 & $\mathrm{Pt}(\mathrm{II})$ ion $+2 \mathrm{Cl}^{-}$ \\
\hline \multirow{2}{*}[\mathrm{Cu}(\mathrm{L1})\mathrm{Cl}_{2}]{} & Hole & 59.034 & 3.915 & 11.890 & 25.160 & $\mathrm{Cu}(\mathrm{II})$ ion $+2 \mathrm{Cl}^{-}$ \\
\hline & Particle & 8.056 & 3.214 & 66.050 & 22.679 & $\mathrm{TSC}+2 \mathrm{Cl}^{-}$ \\
\hline \multirow{2}{*}[\mathrm{Zn}(\mathrm{L}1)\mathrm{Cl}_{2}]{} & Hole & 1.873 & 45.358 & 51.649 & 1.119 & MAP + TSC \\
\hline & Particle & 1.731 & 34.905 & 57.951 & 5.413 & $\mathrm{MAP}+\mathrm{TSC}$ \\
\hline \multicolumn{7}{|c|}{ DMSO } \\
\hline \multirow{2}{*}{ L1 } & Hole & - & 41.677 & 58.323 & - & $\mathrm{MAP}+\mathrm{TSC}$ \\
\hline & Particle & - & 29.818 & 70.182 & - & $\mathrm{MAP}+\mathrm{TSC}$ \\
\hline \multirow{2}{*}[\mathrm{Ni}(\mathrm{L}1)\mathrm{Cl}_{2}]{} & Hole & 19.896 & 37.686 & 36.486 & 5.932 & $\mathrm{Ni}(\mathrm{II})$ ion + MAP + TSC \\
\hline & Particle & 6.189 & 40.681 & 35.610 & 17.520 & $\mathrm{MAP}+\mathrm{TSC}+2 \mathrm{Cl}^{-}$ \\
\hline \multirow{2}{*}[\mathrm{Pd}(\mathrm{L}1)\mathrm{Cl}_{2}]{} & Hole & 34.365 & 25.958 & 24.693 & 14.984 & $\mathrm{Pd}(\mathrm{II})$ ion $+\mathrm{MAP}+\mathrm{TSC}+2 \mathrm{Cl}^{-}$ \\
\hline & Particle & 1.806 & 61.076 & 23.100 & 14.018 & $\mathrm{MAP}+\mathrm{TSC}+2 \mathrm{Cl}^{-}$ \\
\hline \multirow{2}{*}[\mathrm{Pt}(\mathrm{L1})\mathrm{Cl}_{2}]{} & Hole & 5.065 & 60.271 & 33.556 & 1.108 & $\mathrm{MAP}+\mathrm{TSC}$ \\
\hline & Particle & 30.291 & 52.437 & 12.099 & 5.173 & $\mathrm{Pt}(\mathrm{II})$ ion + MAP \\
\hline \multirow{2}{*}[\mathrm{Cu}(\mathrm{L1})\mathrm{Cl}_{2}]{} & Hole & 61.952 & 2.016 & 17.871 & 18.162 & $\mathrm{Cu}(\mathrm{II})$ ion $+\mathrm{TSC}+2 \mathrm{Cl}^{-}$ \\
\hline & Particle & 9.275 & 22.645 & 20.973 & 47.107 & $\mathrm{MAP}+\mathrm{TSC}+2 \mathrm{Cl}^{-}$ \\
\hline \multirow{2}{*}[\mathrm{Zn}(\mathrm{L}1)\mathrm{Cl}_{2}]{} & Hole & 1.932 & 61.449 & 35.673 & 0.945 & MAP + TSC \\
\hline & Particle & 0.714 & 70.615 & 27.791 & 0.880 & MAP + TSC \\
\hline
\end{tabular}

${ }^{\mathrm{a}} \mathrm{M}(\mathrm{II})$ represents the transition metal ions.

${ }^{\mathrm{b}} \mathrm{MAP}$ is the 4-methoxyacetophenone moiety.

${ }^{\mathrm{c}}$ TSC is the thiosemicarbazones moiety.

TABLE 7: Excitation energies and wavelengths, oscillator strengths, NTO eigenvalues, and characters of the dominant electronic transitions for MAPTSC and its complexesin gas-phase and DMSO, calculated at the TD-DFT/CAM-B3LYP/6-31++G(d,p)/(SDD for metal ions) level of theory.

\begin{tabular}{|c|c|c|c|c|c|c|c|c|}
\hline Medium & Molecule & Excited state & Electronic transition $^{\mathrm{a}}$ & NTO eigenvalue & $f$ & $\Delta E(\mathrm{eV})$ & $\lambda_{\max }(\mathrm{nm})$ & Character $^{\mathrm{b}}$ \\
\hline \multirow{6}{*}{ Gas-phase } & $\mathrm{L} 1$ & 2 & $\mathrm{P} \rightarrow \mathrm{H}$ & 0.8866 & 0.4821 & 4.6892 & 264.40 & $n \rightarrow \pi^{*}$ \\
\hline & {$\left[\mathrm{Ni}(\mathrm{Ll}) \mathrm{Cl}_{2}\right]$} & 9 & $\mathrm{P} \rightarrow \mathrm{H}$ & 0.9299 & 0.0342 & 4.1644 & 297.73 & MLCT/LLCT \\
\hline & {$\left[\mathrm{Pd}(\mathrm{L} 1) \mathrm{Cl}_{2}\right]$} & 8 & $\mathrm{P} \rightarrow \mathrm{H}$ & 0.9261 & 0.0557 & 4.1873 & 296.10 & MLCT/LLCT \\
\hline & {$\left[\mathrm{Pt}(\mathrm{L} 1) \mathrm{Cl}_{2}\right]$} & 6 & $\mathrm{P} \rightarrow \mathrm{H}$ & 0.9731 & 0.1224 & 3.8361 & 323.20 & MLCT/LLCT \\
\hline & {$\left[\mathrm{Cu}(\mathrm{L1}) \mathrm{Cl}_{2}\right]$} & 10 & $\mathrm{P} \rightarrow \mathrm{H}$ & 1.6191 & 0.0330 & 3.4788 & 356.40 & LMCT/LLCT \\
\hline & {$\left[\mathrm{Zn}(\mathrm{L1}) \mathrm{Cl}_{2}\right]$} & 2 & $\mathrm{P} \rightarrow \mathrm{H}$ & 0.9265 & 0.5390 & 4.7424 & 261.44 & ILCT \\
\hline \multirow{6}{*}{ DMSO } & L1 & 2 & $\mathrm{P} \rightarrow \mathrm{H}$ & 0.9190 & 0.7898 & 4.7279 & 262.24 & $n \rightarrow \pi^{*} / \pi \rightarrow \pi^{*}$ \\
\hline & {$\left[\mathrm{Ni}(\mathrm{L1}) \mathrm{Cl}_{2}\right]$} & 8 & $\mathrm{P} \rightarrow \mathrm{H}$ & 0.6493 & 0.3197 & 4.5408 & 273.04 & LMCT/ILCT/LLCT \\
\hline & {$\left[\mathrm{Pd}(\mathrm{L} 1) \mathrm{Cl}_{2}\right]$} & 7 & $\mathrm{P} \rightarrow \mathrm{H}$ & 0.8746 & 0.3549 & 4.4265 & 280.10 & LMCT/ILCT/LLCT \\
\hline & {$\left[\mathrm{Pt}(\mathrm{L} 1) \mathrm{Cl}_{2}\right]$} & 6 & $\mathrm{P} \rightarrow \mathrm{H}$ & 0.9330 & 0.3691 & 4.4592 & 278.04 & MLCT/ILCT \\
\hline & {$\left[\mathrm{Cu}(\mathrm{L1}) \mathrm{Cl}_{2}\right]$} & 10 & $\mathrm{P} \rightarrow \mathrm{H}$ & 1.7312 & 0.0305 & 3.4829 & 355.98 & LMCT/ILCT/LLCT \\
\hline & {$\left[\mathrm{Zn}(\mathrm{L1}) \mathrm{Cl}_{2}\right]$} & 1 & $\mathrm{P} \rightarrow \mathrm{H}$ & 0.9575 & 0.7015 & 4.5399 & 273.10 & ILCT \\
\hline
\end{tabular}

\footnotetext{
a $\mathrm{P}$ stands for "particle" and $\mathrm{H}$ stands for "hole."
}

${ }^{\mathrm{b}} n$ represents occupied lone pair orbitals. 


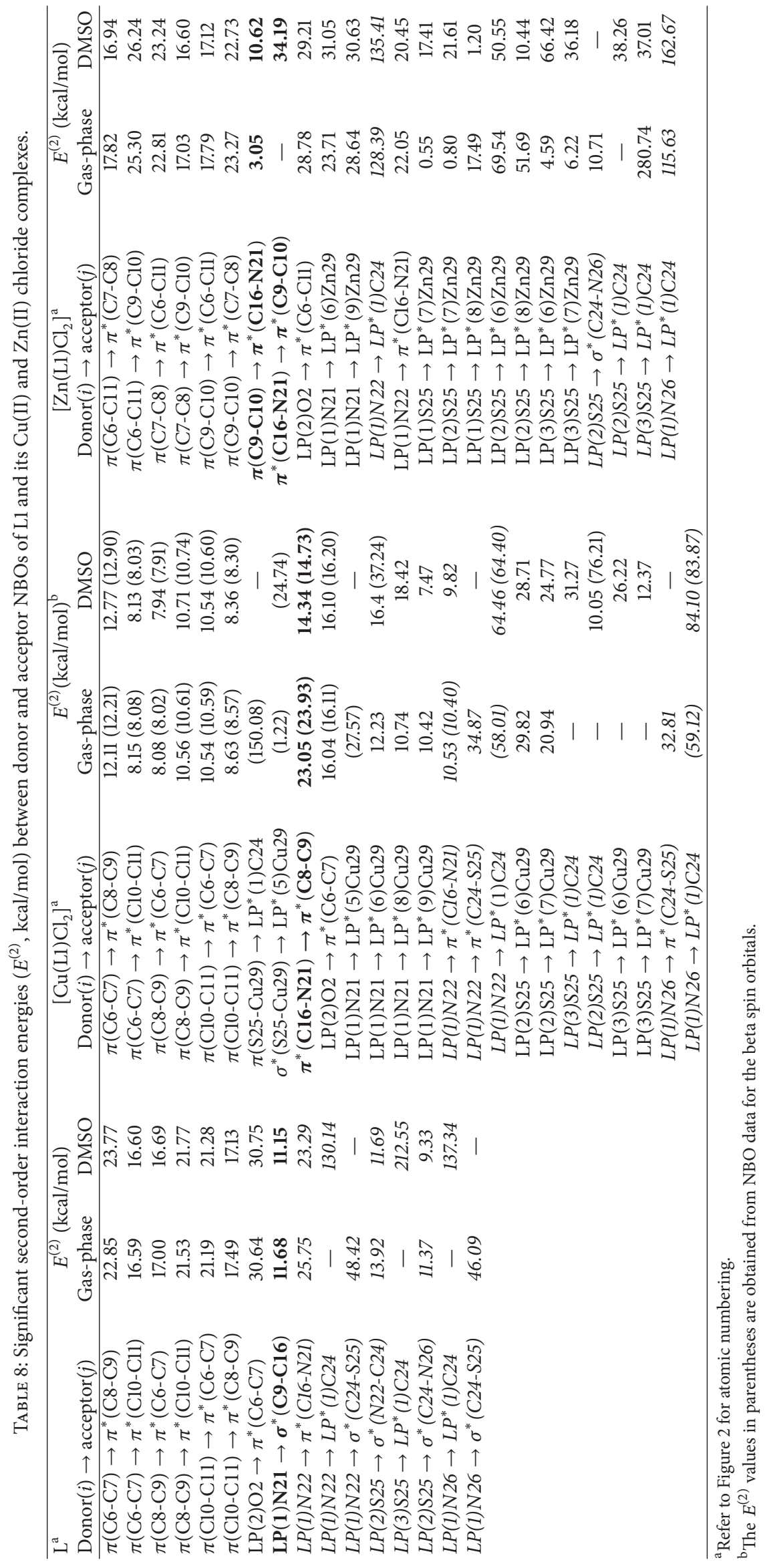




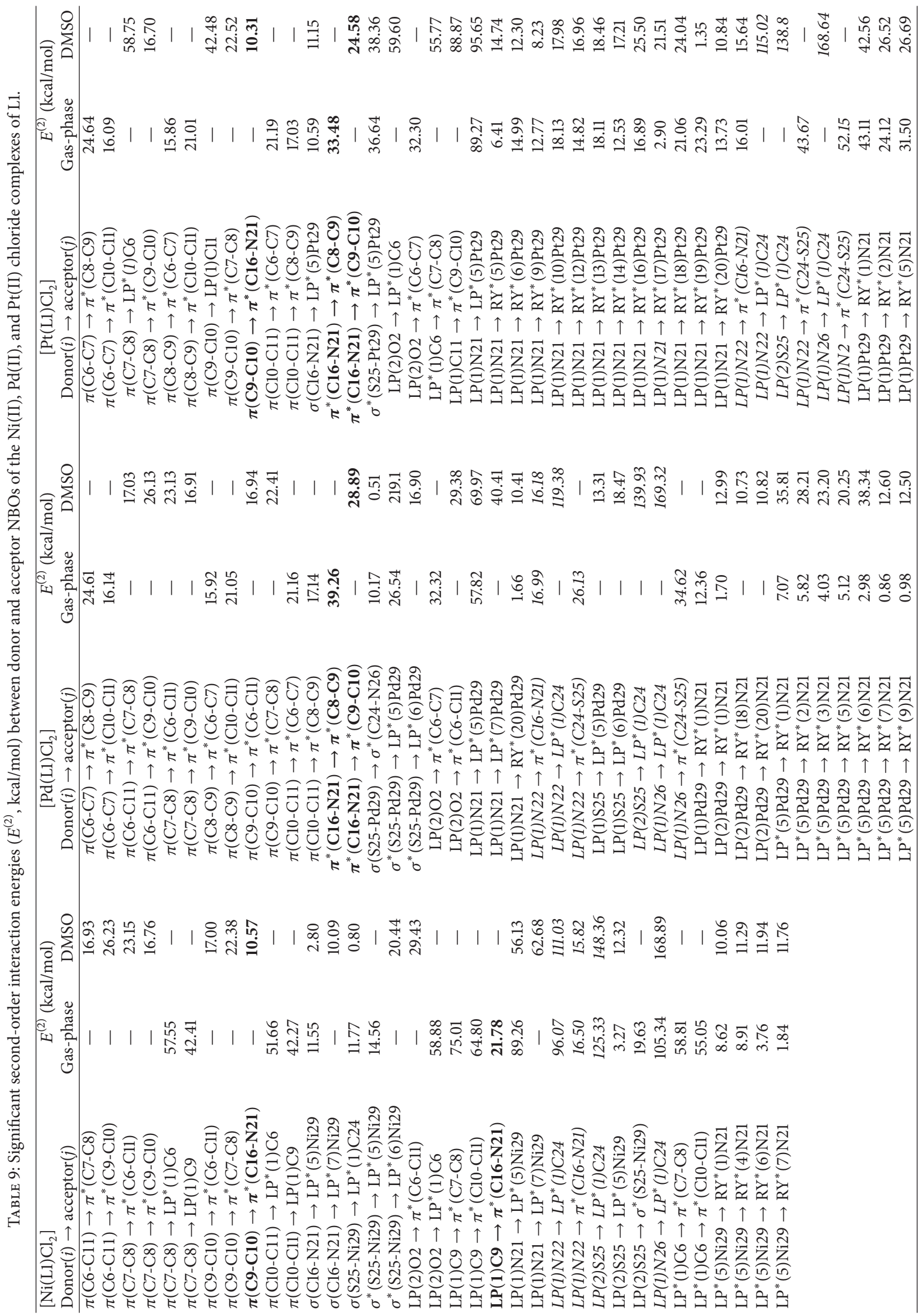




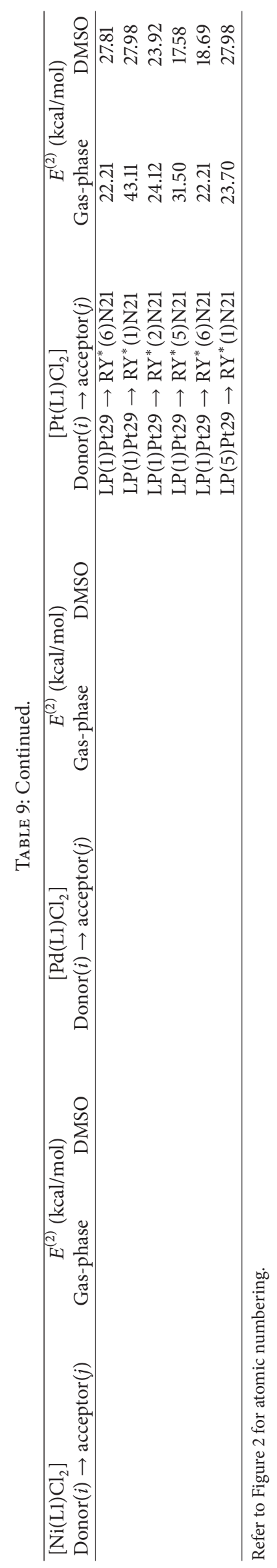


complex is found to be extended from the benzene ring to the TSC moiety by the intensive hyperconjugative interactions $\pi(\mathrm{C} 9-\mathrm{C} 10) \rightarrow \pi^{*}(\mathrm{C} 16-\mathrm{N} 21), \pi^{*}(\mathrm{C} 16-\mathrm{N} 21) \rightarrow \pi^{*}(\mathrm{C} 9-\mathrm{C} 10)$, $\pi^{*}(\mathrm{C} 16-\mathrm{N} 21) \rightarrow \pi^{*}(\mathrm{C} 8-\mathrm{C} 9), \mathrm{LP}(1) \mathrm{N} 21 \rightarrow \sigma^{*}$ (C9-C16), and $\mathrm{LP}(1) \mathrm{C} 9 \rightarrow \pi^{*}(\mathrm{C} 16-\mathrm{N} 21)$. These are boldly highlighted in Tables 8 and 9.

Strong hyperconjugative interactions (italicized in Tables 8 and 9) predominate in the TSC moieties of all investigated molecules, giving rise to extensive electron delocalization that greatly improves the SHG efficiencies of the molecules. On the basis of their $E^{(2)}$ values, the strengths of the NBO interactions in all molecules studied are found to increase upon transition from the gas to the solvent phase. This partially accounts for the significant first hyperpolarizability increments of these molecules in the solvent environment. Strong donor-acceptor NBO interactions are found between the donor atoms (N21 and S25) of L1 and the transition metal ions in the $\mathrm{MCl}_{2}$ fragments. The electrons donated by N21 and S25 are received in vacant metal-based lone pair $\left(\mathrm{LP}^{*}\right)$ and Rydberg $\left(\mathrm{RY}^{*}\right)$ orbitals. On the other hand, back donated electrons from the metal ions are mainly received in $\mathrm{RY}^{*}$ orbitals on N21. Back donation of electrons is highly significant in the $\mathrm{Pd}(\mathrm{II})$ and $\mathrm{Pt}(\mathrm{II})$ chloride complexes of L1 and minimal in the rest of the complexes, confirming the results earlier obtained from CDA analysis. Both CDA and $\mathrm{NBO}$ analyses have shown that the $\mathrm{Pd}(\mathrm{II})$ and $\mathrm{Pt}(\mathrm{II})$ ions can function as ambivalent electron donors and acceptors, while the $\mathrm{Ni}(\mathrm{II}), \mathrm{Cu}(\mathrm{II})$, and $\mathrm{Zn}$ (II) ions may only act as electron acceptors in their respective complexes investigated herein. It is also clear from $\mathrm{NBO}$ analysis that the $\pi$-conjugated pathways of these push-pull systems are comprised of the benzene ring and the attached TSC moieties.

\section{Conclusion}

Transition metal complexes containing $\pi$-conjugated organic ligands are less investigated for NLO applications despite their potentials of combining the high optical nonlinearity and chemical flexibility of organic materials with the physical strength of inorganic materials. Against this backdrop, the linked effects of transition metal chelation and solvent polarity on the first molecular hyperpolarizability $\left(\beta_{\text {tot }}\right)$ of MAPTSC have been investigated herein via DFT calculations. Our results have revealed significant modifications of the $\beta_{\text {tot }}$ value for MAPTSC upon complexation with different transition metal chlorides in the presence of solvents with varying dielectric constants. Therefore, its second-order NLO response is highly tunable by the synergy of transition metal chelation and solvent polarity. In gas-phase, the $\beta_{\text {tot }}$ value for the thione tautomer of MAPTSC (L1) increases upon complexation with $\mathrm{Pt}(\mathrm{II})$ and $\mathrm{Zn}$ (II) chlorides, but decreases following its complexation with $\mathrm{Ni}(\mathrm{II}), \mathrm{Pd}(\mathrm{II})$, and $\mathrm{Cu}(\mathrm{II})$ chloride complexes. Nevertheless, the complexation of L1 with these transition metal chlorides in polar solvents results in modest to drastic first hyperpolarizability increments in nearly all cases studied. Based on these findings, it can be concluded that the complexation of a purely organic push-pull system with a transition metal center may not always improve upon its first hyperpolarizability vis-a-vis the
NLO response, especially in the absence of a polar solvent. MAPTSC and its $\mathrm{Zn}$ (II) and Pt(II) chloride complexes have been identified as promising NLO materials because their gas-phase $\beta_{\text {tot }}$ values are larger than those of the prototype push-pull molecules para-nitroaniline (PNA) and urea by factors of about 1.40-1.76 and 19.57-37.24, respectively; these factors greatly increase in polar solvent medium. Moreover, they have high optical transparencies in the visible region of the electromagnetic spectrum which greatly overcomes transparency/nonlinearity trade-offs that often lead to lower device efficiency and reduced photostability.

\section{Competing Interests}

The authors declare that there are no competing interests regarding the publication of this paper.

\section{Acknowledgments}

This work has been supported by a prospective joint research assistance sponsored by a CV Raman International Fellowship for African Researchers justifiable at IIT Kanpur, India (Grant no. 101F102), by the Ministry of External Affairs of India and FICCI (Federation of Indian Chambers of Commerce and Industry) for which the authors are grateful.

\section{References}

[1] T. Thilak, M. B. Ahamed, and G. Vinitha, "Third order nonlinear optical properties of potassium dichromate single crystals by Zscan technique," Optik, vol. 124, no. 21, pp. 4716-4720, 2013.

[2] W.-Y. Wang, X.-F. Du, N.-N. Ma, S.-L. Sun, and Y.-Q. Qiu, "Theoretical investigation on switchable second-order nonlinear optical (NLO) properties of novel cyclopentadienylcobalt linear [4]phenylene complexes," Journal of Molecular Modeling, vol. 19, no. 4, pp. 1779-1787, 2013.

[3] C. Wang, C. Chen, Q. Zhang, D. Qi, and J. Jiang, "Nature of second-order nonlinear optical response in phthalocyanine derivatives: a density functional theory study," Turkish Journal of Chemistry, vol. 38, no. 6, pp. 1046-1055, 2014.

[4] A. Al-Yasari, N. Van Steerteghem, H. El Moll, K. Clays, and J. Fielden, "Donor-acceptor organo-imido polyoxometalates: high transparency, high activity redox-active NLO chromophores," Dalton Transactions, vol. 45, no. 7, pp. 2818-2822, 2016.

[5] R. Renjith, Y. S. Mary, C. Y. Panicker et al., "Spectroscopic (FT-IR, FT-Raman), first order hyperpolarizability, NBO analysis, HOMO and LUMO analysis of 1,7,8,9-tetrachloro10,10-dimethoxy-4-[3-(4-phenylpiperazin-1-yl)propyl]-4azatricyclo[5.2.1.0 $\left.0^{2,6}\right]$ dec-8-ene-3,5-dione by density functional methods," Spectrochimica Acta Part A, vol. 124, pp. 500-513, 2014.

[6] R. N. Singh and P. Rawat, "Spectral analysis, structural elucidation, and evaluation of both nonlinear optical properties and chemical reactivity of a newly synthesized ethyl-3,5-dimethyl-4-[(toluenesulfonyl)-hydrazonomethyl]$1 \mathrm{H}$-pyrrole-2-carboxylate through experimental studies and quantum chemical calculations," Journal of Molecular Structure, vol. 1054-1055, pp. 65-75, 2013.

[7] J. Binoy, M. K. Marchewka, and V. S. Jayakumar, "The 'partial resonance' of the ring in the NLO crystal melaminium formate: 
study using vibrational spectra, DFT, HOMO-LUMO and MESP mapping," Spectrochimica Acta-Part A: Molecular and Biomolecular Spectroscopy, vol. 104, pp. 97-109, 2013.

[8] Z. B. Liu, X. L. Zhang, X. Q. Yan, Y. S. Chen, and J. G. Tian, "Nonlinear optical properties of graphene-based materials," Chinese Science Bulletin, vol. 57, no. 23, pp. 2971-2982, 2012.

[9] K. S. Thanthiriwatte and K. M. Nalin de Silva, "Non-linear optical properties of novel fluorenyl derivatives-Ab initio quantum chemical calculations," Journal of Molecular Structure: THEOCHEM, vol. 617, pp. 169-175, 2002.

[10] P. Agarwal, N. Choudhary, A. Gupta, and P. Tandon, "Density functional theory studies on the structure, spectra (FTIR, FT-Raman, and UV) and first order molecular hyperpolarizability of 2-hydroxy-3-methoxy-N-(2-chloro-benzyl)benzaldehyde-imine: comparison to experimental data," Vibrational Spectroscopy, vol. 64, pp. 134-147, 2013.

[11] Z. Demircioğlu, Ç. A. Kaştaş, and O. Büyükgüngör, "The spectroscopic (FT-IR, UV-vis), Fukui function, NLO, NBO, NPA and tautomerism effect analysis of (E)-2-[(2-hydroxy-6methoxybenzylidene)amino]benzonitrile," Spectrochimica Acta Part A, vol. 139, pp. 539-548, 2015.

[12] Y. Si, G. Yang, and Z. Su, "Chiroptical, linear, and secondorder nonlinear optical properties of tetrathiafulvalenylallene: a multifunctional molecular material," Journal of Materials Chemistry C, vol. 1, no. 7, pp. 1399-1406, 2013.

[13] N. S. Labidi, "Nonlinear optical properties of novel mono-Ohydroxy bidentate schiff base: quantum chemical calculations," International Journal of Metals, vol. 2013, Article ID 964328, 5 pages, 2013.

[14] H. Alyar, "A review on nonlinear optical properties of donoracceptor derivatives of naphthalene and azanaphthalene," Reviews on Advanced Materials Science, vol. 34, no. 1, pp. 7987,2013

[15] F. Khammar, A. P. Kerasidou, K. Iliopoulos et al., "Effect of metal complexation on the nonlinear optical response of a conjugated ligand," Journal of the Optical Society of America B: Optical Physics, vol. 31, no. 7, pp. 1555-1560, 2014.

[16] S. A. Khan, A. M. Asiri, K. Al-Amry, and M. A. Malik, "Synthesis, characterization, electrochemical studies, and in vitro antibacterial activity of novel thiosemicarbazone and its $\mathrm{Cu}(\mathrm{II}), \mathrm{Ni}(\mathrm{II})$, and $\mathrm{Co}(\mathrm{II})$ complexes," The Scientific World Journal, vol. 2014, Article ID 592375, 9 pages, 2014.

[17] R. Santhakumari, K. Ramamurthi, G. Vasuki, B. M. Yamin, and G. Bhagavannarayana, "Synthesis and spectral characterization of acetophenone thiosemicarbazone-a nonlinear optical material," Spectrochimica Acta Part A: Molecular and Biomolecular Spectroscopy, vol. 76, no. 3-4, pp. 369-375, 2010.

[18] R. Kothari and B. Sharma, "Characterization, antibacterial, antifungal, antioxidant and DNA interaction studies of TSC transition metal complexes," World Journal of Pharmacy and Pharmaceutical Sciences, vol. 3, no. 7, pp. 1067-1080, 2014.

[19] E. G. Lewars, Computational Chemistry: Introduction to the Theory and Applications of Molecular and Quantum Mechanics, Springer, New York, NY, USA, 2nd edition, 2011.

[20] M. J. Frisch, G. W. Trucks, H. B. Schlegel et al., Gaussian 09, Revision A.02, Gaussian, Inc, Wallingford, Conn, USA, 2009.

[21] A. D. Becke, "Density-functional thermochemistry. III. The role of exact exchange," The Journal of Chemical Physics, vol. 98, no. 7, pp. 5648-5652, 1993.

[22] R. L. Martin, "Natural transition orbitals," Journal of Chemical Physics, vol. 118, no. 11, pp. 4775-4777, 2003.
[23] M. Karnan, V. Balachandran, M. Murugan, M. K. Murali, and A. Nataraj, "Vibrational (FT-IR and FT-Raman) spectra, NBO, HOMO-LUMO, Molecular electrostatic potential surface and computational analysis of 4-(trifluoromethyl)benzylbromide," Spectrochimica Acta Part A, vol. 116, pp. 84-95, 2013.

[24] H.-B. Liu, Y.-Q. Qiu, G.-C. Yang, C.-G. Liu, and S.-L. Sun, "Effects of electron donor and different solvents on polarizability and second hyperpolarizability of diradical complex involving X (X = B, Al, Ga)," Chemical Research in Chinese Universities, vol. 28, no. 2, pp. 308-312, 2012.

[25] A. Srivastava, R. Mishra, S. Kumar, K. Dev, P. Tandon, and R. Maurya, "Molecular structure, spectral investigation $\left({ }^{1} \mathrm{H}\right.$ NMR, ${ }^{13} \mathrm{C}$ NMR, UV-Visible, FT-IR, FT-Raman), NBO, intramolecular hydrogen bonding, chemical reactivity and first hyperpolarizability analysis of formononetin [7-hydroxy3(4-methoxyphenyl)chromone]: a quantum chemical study," Journal of Molecular Structure, vol. 1084, pp. 55-73, 2015.

[26] S. Ramalingam, M. Karabacak, S. Periandy, N. Puviarasan, and D. Tanuja, "Spectroscopic (infrared, Raman, UV and NMR) analysis, Gaussian hybrid computational investigation (MEP maps/HOMO and LUMO) on cyclohexanone oxime," Spectrochimica Acta Part A, vol. 96, pp. 207-220, 2012.

[27] J. G. Małecki, A. Maroń, M. Serda, and J. Polański, "Ruthenium(II) carbonyl complexes with thiosemicarbazone ligands," Polyhedron, vol. 56, pp. 44-54, 2013.

[28] R. Harness, C. Robertson, and F. Beckford, "Thiosemicarbazone complexes of group 12 elements. An investigation of the thiosemicarbazone from p-dimethylaminobenzaldehyde," Journal of Undergraduate Chemistry Research, vol. 7, no. 3, pp. 92-97, 2008.

[29] R. D. Dennington II, T. A. Keith, and J. M. Millam, Gauss View 5.0.8, Gaussian, Inc, Wallingford, Conn, USA, 2009.

[30] S. Dapprich and G. Frenking, "Investigation of donor-acceptor interactions: a charge decomposition analysis using fragment molecular orbitals," Journal of Physical Chemistry, vol. 99, no. 23, pp. 9352-9362, 1995.

[31] M. Xiao and T. Lu, "Generalized Charge Decomposition Analysis (GCDA) method," Journal of Advances in Physical Chemistry, vol. 4, no. 4, pp. 111-124, 2015.

[32] S. I. Gorelsky, S. Ghosh, and E. I. Solomon, "Mechanism of $\mathrm{N}_{2} \mathrm{O}$ reduction by the $\mu_{4}$-S tetranuclear $\mathrm{Cu}_{\mathrm{Z}}$ cluster of nitrous oxide reductase," Journal of the American Chemical Society, vol. 128, no. 1, pp. 278-290, 2006.

[33] R. Z. Khaliullin, A. T. Bell, and M. Head-Gordon, "Analysis of charge transfer effects in molecular complexes based on absolutely localized molecular orbitals," Journal of Chemical Physics, vol. 128, no. 18, pp. 184112-184128, 2008.

[34] T. Lu and F. Chen, "Multiwfn: a multifunctional wavefunction analyzer," Journal of Computational Chemistry, vol. 33, no. 5, pp. 580-592, 2012.

[35] P. Song, C. Liu, W. Guan et al., “Theoretical investigation of second-order nonlinear optical response-Hexamolybdate as a superior donor over metal carbonyl complexes in the D- $\pi-\mathrm{A}$ model," Canadian Journal of Chemistry, vol. 89, no. 1, pp. 61-67, 2011.

[36] L. Jensen and P. T. van Duijnen, "The first hyperpolarizability of p-nitroaniline in 1,4-dioxane: a quantum mechanical/molecular mechanics study," Journal of Chemical Physics, vol. 123, no. 7, pp. 074307-074314, 2005.

[37] T. Sivaranjani, S. Xavier, and S. Periandy, "NMR, FT-IR, FTRaman, UV spectroscopic, HOMO-LUMO and NBO analysis 
of cumene by quantum computational methods," Journal of Molecular Structure, vol. 1083, pp. 39-47, 2015.

[38] S. Stoyanov, I. Petkov, L. Antonov, T. Stoyanova, P. Karagiannidis, and P. Aslanidis, "Thione-thiol tautomerism and stability of 2- and 4-mercaptopyridines and 2-mercaptopyrimidines," Canadian Journal of Chemistry, vol. 68, no. 9, pp. 1482-1489, 1990.

[39] X. Shan, A. O. Ibrahim, Y. Zhou et al., "Luminescent, secondorder NLO and magnetic properties of the hydrogen-bond based network derived from 2,2' -bipyridine-6,6'-dicarboxylate," Inorganic Chemistry Communications, vol. 22, pp. 149153, 2012.

[40] W. Humphrey, A. Dalke, and K. Schulten, "VMD: visual molecular dynamics," Journal of Molecular Graphics, vol. 14, no. 1, pp. 33-38, 1996.

[41] T. Lu and F. Chen, "Calculation of molecular orbital composition," Acta Chimica Sinica, vol. 69, no. 20, pp. 2393-2406, 2011.

[42] E. D. Glendening, A. E. Reed, J. E. Carpenter, and F. Weinhold, NBO Version 3.1, Gaussian Inc, Wallingford, Conn, USA, 2003.

[43] V. D. Vitnik, Ž. J. Vitnik, N. R. Banjac, N. V. Valentić, G. S. Ušcumlić, and I. O. Juranić, "Quantum mechanical and spectroscopic (FT-IR, 13C, 1H NMR and UV) investigations of potent antiepileptic drug 1-(4-chloro-phenyl)-3- phenyl-succinimide," Spectrochimica Acta-Part A: Molecular and Biomolecular Spectroscopy, vol. 117, pp. 42-53, 2014. 

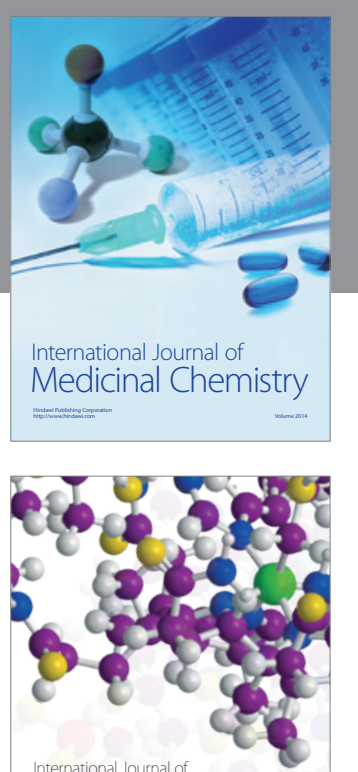

Carbohydrate Chemistry

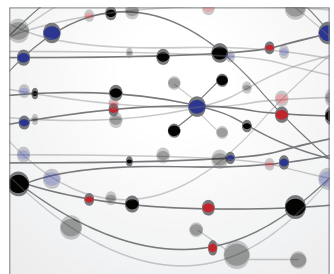

The Scientific World Journal
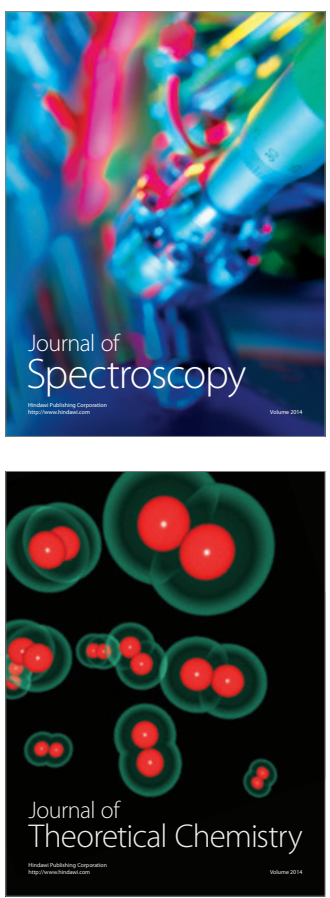
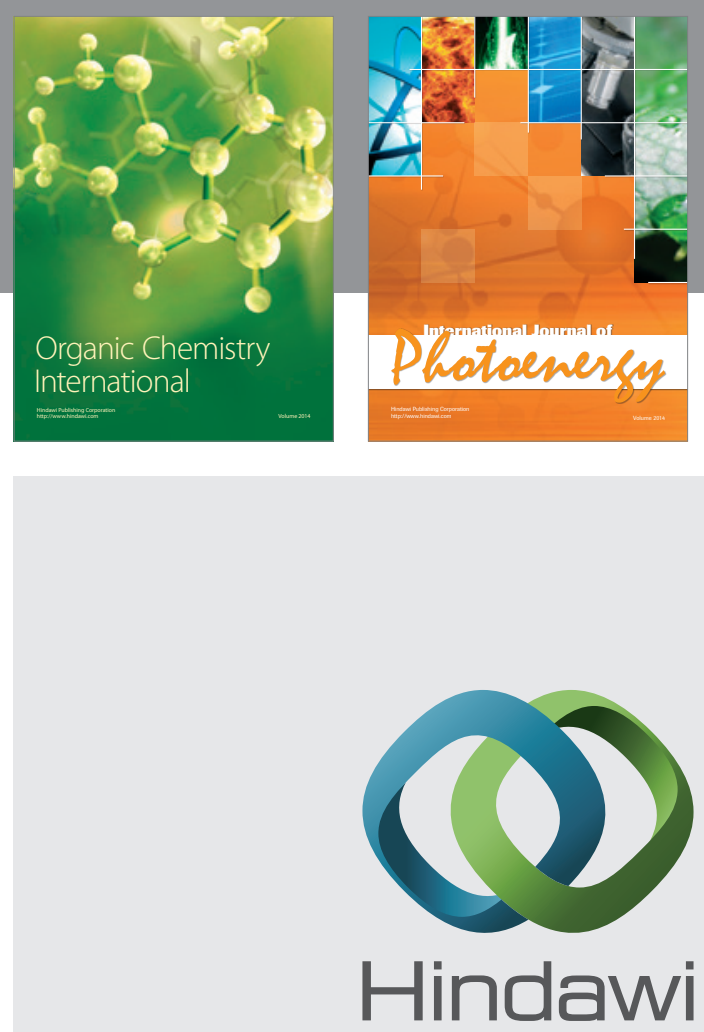

Submit your manuscripts at

http://www.hindawi.com

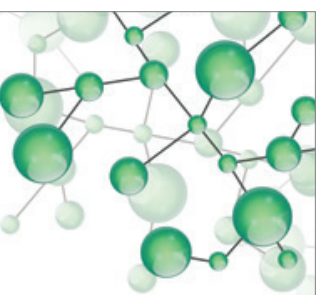

International Journal of

Inorganic Chemistry

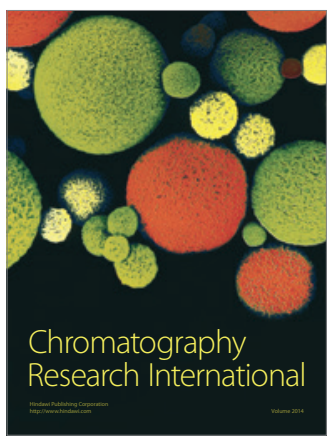

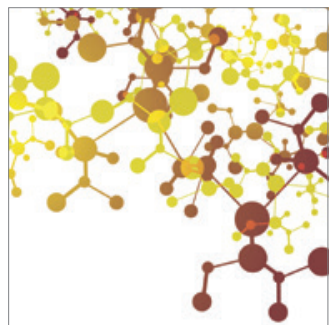

Applied Chemistry
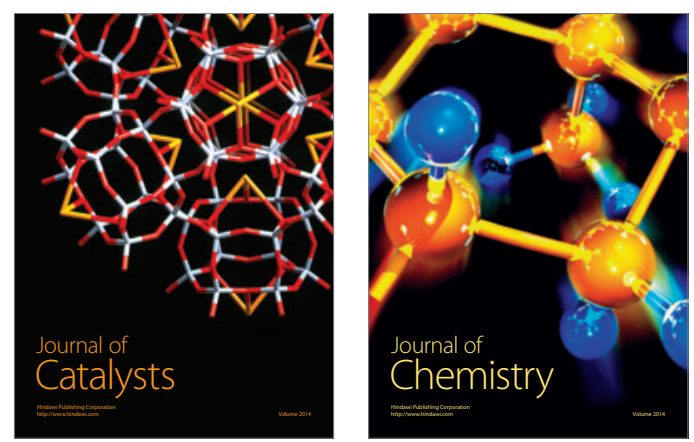
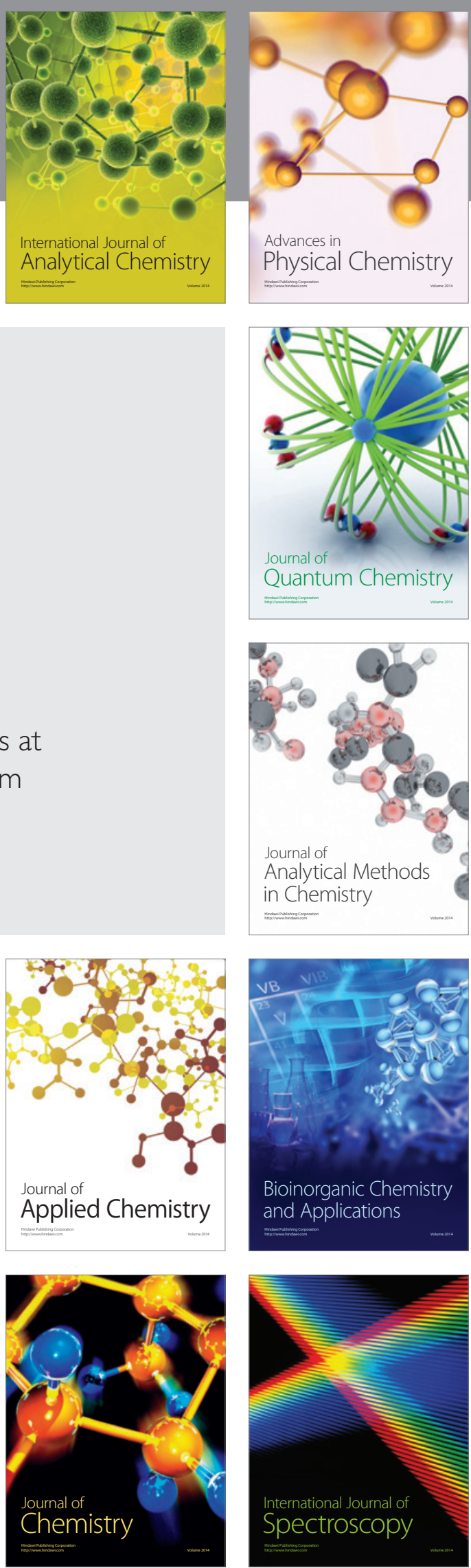